\title{
9 „Wie werde ich reich und glücklich?“ Ein Glücksratgeber als Ausweg aus der Krise in der Kabarettrevue von Felix Joachimson
}

Der Glücksratgeber „Wie werde ich reich und glücklich? Ein Kursus in 10 Abteilungen“ in Felix Joachimsons (1902-1993) gleichnamiger Kabarettrevue ${ }^{1}$, die 1930 in Berlin uraufgeführt wurde, dient als Einstieg, um einen ersten Einblick in das dynamische Diskursfeld über Glückswissen zwischen 1930 und 1945 zu erhalten. ${ }^{2}$ Der Ausgangpunkt der Handlung ist die Gesellschaft der Weimarer Republik, die sich aufgrund der Demokratisierungsprozesse seit dem Ende des Ersten Weltkriegs und mit dem Börsenkrach von 1929 in einer selbstdiagnostizierten „Krise“ befindet. ${ }^{3}$ Der fiktive Ratgeber von Dr. Pauspack mit Leitsätzen zum Erlangen von A. Reichtum oder B. „Glück“ verspricht, die Protagonist*innen der Kabarettrevue aus ihren wirtschaftlichen und individuellen Krisen herauszuführen (Leitsätze s. Abb. 3).

Warum ist dieser Untersuchungsgegenstand zur Analyse einer transnationalen Politik der ,Glückskulturen‘ aufschlussreich? ,Theater' war in der Weimarer Republik ein Leitmedium. Als Spiegel der Gesellschaft diente die Theateraufführung der kritischen Auseinandersetzung mit gesellschaftspolitischen Themen

1 Zum Begriff der Kabarettrevue, vgl. Becker 1996.Vgl. Art. Revue (MMG2): „Bei der Revue handelt es sich um ein musiktheatrales Genre, das, im frühen 19. Jh. entstanden, in den Jahrzehnten vor dem Zweiten Weltkrieg seine größte Popularität erlangte und als typisches Phänomen der modernen Großstadt gelten kann. Die Vielfalt seiner Ausprägungen macht eine klare Definition schwierig. Als nahezu durchgängige Merkmale können allerdings gelten: in struktureller Hinsicht die Aneinanderreihung von Nummern, die durch ein Rahmenthema und/oder durch eine spezifische Form von Conférence in Gestalt der sog. Compère- bzw. Commère-Figuren zusammengehalten werden, in inhaltlicher Hinsicht die heitere bis satirische Auseinandersetzung mit aktuellen Ereignissen, die sich in den unterschiedlichen Spielarten der Jahresrevue als Überblick über politische und/oder gesellschaftliche und/oder künstlerische Ereignisse der vergangenen Saison darstellt. [...]“ Vgl. Linhardt 2016. Im Folgenden wird der Begriff Kabarettrevue verwendet, um die ästhetischen Mittel des Kabaretts zu betonen, mit denen die Gattung Revue bei Joachimson auch satirisch parodiert wird. S. auch Begriff Musiksatire w.u.

2 Felix Joachimson. 1930. „Wie werde ich reich und glücklich. Ein Kursus in 10 Abteilungen“. Mit Musik von Mischa Spoliansky. Berlin: Rondo-Verlag [Als unverkäufliches Manuskript gedruckt], 7, Felix Bloch Erben Archiv, Berlin. [Abk.: Joachimson 1930]. Das Quellenmaterial für die Analyse in Kap. 9 bezieht sich auf die Bestände des Archivs der Akademie der Künste in Berlin sowie des Archivs der Felix-Bloch-Erben in Berlin (Wie werde ich reich und glücklich? Ein Kursus in zehn Abteilungen. Buch von Felix Joachimson. Musik von Misch Spoliansky (C) und Aufführungsrechte bei Felix Bloch Erben GmbH \& Co. KG, Berlin | www.felix-bloch-erben.de).

3 Zum Krisendiskurs in der Weimarer Republik vgl. Eitz 2015, Eitz und Engelhardt 2015.

Ә OpenAccess. (c) 2021 Isabelle Haffter, publiziert von De Gruyter. (cc))BY-NC-ND Dieses Werk ist lizenziert unter einer Creative Commons Namensnennung - Nicht kommerziell - Keine Bearbeitung 4.0 International Lizenz. https://doi.org/10.1515/9783110661439-009 

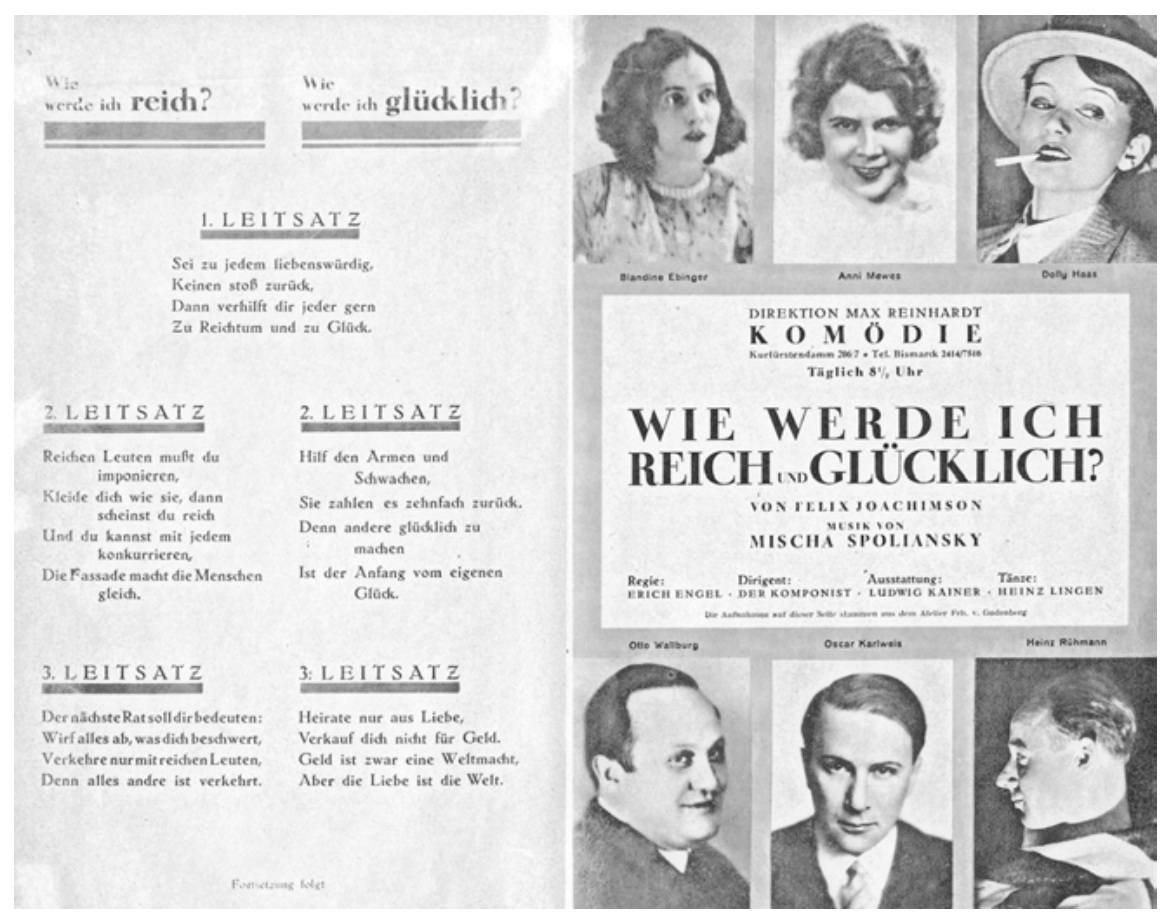

Abb. 3: „Wie werde ich reich und glücklich?“ von Felix Joachimson, Musik: Mischa Spoliansky, Regie: Erich Engel, [Programmheft], Komödie am Kurfürstendamm, Berlin, 1930

und Fragestellungen. Die Handlung der Kabarettrevue kann exemplarisch für die Krisendiagnose der Weimarer Republik um 1930 stehen. Der Glücksratgeber dient in der Handlung als diskursives Wissensmedium über "Glück“ und „Erfolg“. Joachimsons Aufführung der Kabarettrevue kann folglich als kritische Reflexion über eine Politik von ,Glückskulturen` begriffen werden. Die folgende Analyse soll diese These unter Beweis stellen.

\subsection{Der Ratgeber „Wie werde ich reich und glücklich?“ in Joachimsons Kabarettrevue}

Eines Tages wird dem arbeitslosen 26-jährigen Kibis per Post ein Werbeschreiben eines Herrn „Dr. C. M. Pausback“ zusammen mit einer Ratgeberbroschüre zugeschickt: 
„Sehr geehrter Herr, ich erlaube mir, Ihnen aus Reklamegründen meine neue Broschüre ,Wie werde ich reich und glücklich` unentgeltlich zur Verfügung zu stellen. Leben Sie nach den von mir in populärer, leichtfasslicher Form aufgestellten Elementgrundsätzen [sic], und der Erfolg wird nicht ausbleiben. Erst dann veranlassen Sie Ihren werten Bekanntenkreis die beiliegende Broschüre von mir zu beziehen. Preis zuzüglich Portospesen Mk. 1,20, N 31 Brunnenstrasse 2. Mit dem Ausdruck vorzüglichster Hochachtung ganz ergebenst.“ ${ }^{4}$

Der Titel der Ratgeberbroschüre lautet verheißungsvoll „Wie werde ich reich und glücklich?" und verspricht nicht weniger als mit der Anleitung von 10 Leitsätzen die Leser`innen, je nach Bedarf, A. reich oder B. „glücklich“ zu machen. „[...] komischer Titel“, sagt sich Kibis und beginnt neugierig in der Broschüre zu lesen.

Kibis ist die männliche Hauptfigur in der am 15. Mai 1930 in der „Komödie am Kurfürstendamm“ in Berlin uraufgeführten Kabarettrevue „Wie werde ich reich und glücklich? Ein Kursus in 10 Abteilungen“ von Felix Joachimson unter der Regie von Erich Engel (1891-1966) und dem Dirigat des Komponisten Mischa Spoliansky (1898-1985). ${ }^{5}$ Das Stück war ein Publikumserfolg und wurde noch im selben Jahr als Spielfilm unter der Regie von Max Reichmann (1884-1958) im Kino gezeigt. ${ }^{6}$ Worin mag der Erfolg der Kabarettrevue gelegen haben? Zur Beantwortung dieser Frage wird das im Theatertext angelegte Glückswissen unter-

4 Joachimson 1930, 3.

5 Joachimson 1930. Laut aktuellem Forschungsstand der Autorin handelt es sich um ein Forschungsdesiderat. Kurze Erwähnung der Kabarettrevue vgl. Stahrenberg 2012, 155f. Das Premierenensemble: Oskar Karlweis (Kibis), Annie Mewes (Marie Regen), Blandine Ebinger (Lis Ruppke), Dolly Haas (stumme Conférencière), Otto Wallburg (Geheimrat Regen) und Heinz Rühmann (F. D. Lohrenz). Choreografie: Heinz Lingen, Ausstattung: Ludwig Kainer, vgl. Programmheft, Spoliansky 262, Mischa-Spoliansky-Archiv, Archiv AdK, 5.02 Druckschriften. Zu Joachimson vgl. Asper 2015. Nachdem der gebürtige Hamburger Felix Joachimson (1902-1993) in Freiburg i.B. Jura und Wirtschaft studiert hatte, war er seit 1923 in Berlin als Journalist, u.a. als Theaterkritiker, und als erfolgreicher Bühnen- und Drehbuchautor tätig. Nach der Machtergreifung der Nationalsozialisten emigrierte J. über Budapest und Wien schließlich im Februar 1937 in die USA, wo er unter dem Namen Felix Jackson in der amerikanischen Unterhaltungsfilmbranche als Drehbuchautor und Produzent Fuß fassen konnte. Seine Erlebnisse in NS-Deutschland verarbeitete Jackson erstmals in der autobiografischen Novelle „So help me God“, die 1955 bei Viking Press (New York) erschien. 1980 veröffentlichte J. seinen zweiten autobiografischen Roman „Secret of Blood“ (Dt. Übersetzung, „Berlin, April 1933“, Aachen: Alano Verlag 1993), der 2018 neuaufgelegt wurde, vgl. Jackson 2018. Zu Spoliansky vgl. Kühn 2010, Stahrenberg 2012, Weniger 2011a. Zu Erich Engel besteht noch ein relatives Forschungsdesiderat, vgl. u. a. Aurich 1998. Das Erich-Engel-Archiv befindet sich im Archiv der Adk, https://archiv.adk.de/bigobjekt/116, 20.01. 2020.

6 Die Darsteller^innen: Hugo Schrader (Kibis), Ilse Korseck (Marie), Georgia Lind (Lis), Paul Hörbiger (Geheimrat Regen) und Willy Stettner (F. D. Lorenz). Zur filmischen Rezeption vgl. Graf 2018. Zu Reichmann, vgl. Weniger 2001. 
sucht und in den gesellschaftspolitischen und theaterhistorischen Kontext der Weimarer Republik gestellt. Dafür wird ein Vergleich zu den zeitgenössischen Überlegungen des Wissenssoziologen Karl Mannheim (1893-1947) in „Utopie und Ideologie“ (1929) angestellt.7 Quellenbegriffe wie „Glück“, „Freude“ und „Lebensführung“ werden dabei quellenkritisch analysiert und in den spezifischen historischen Kontext der jeweiligen Glückspraktiken gestellt.

Auf der Ebene des Theatertexts wird die Handlungsstruktur hinsichtlich sprachlicher und, soweit theaterhistorisch rekonstruierbar, theaterästhetischer Mittel untersucht und mit der literarischen Vorlage „Kleider machen Leute“ von Gottfried Keller (1819-1890) verglichen. ${ }^{8}$ Mit Blick auf die Figurenkonstellationen werden die verschiedenen Geschlechterstereotypen anhand ihrer Handlungsweisen und Charakterbeschreibungen emotions- und wissenshistorisch analysiert und in den Rezeptionskontext der zeitgenössischen Theaterkritik gestellt. Das Ziel der Untersuchung ist es, Erkenntnisse über die unterschiedlichen Vorstellungen von „Glück“, „Lebensführung“ und „Reichtum“ am Ende der Weimarer Republik zu erhalten, um in der Folge den wissenshistorischen Wandel von Glückswissen nach 1933 aufzeigen zu können.

\subsection{Zur Handlung der Kabarettrevue}

Frei nach Gottfried Kellers Novelle „Kleider machen Leute“9 entwarf Joachimson die Kabarettrevue „Wie werde ich reich und glücklich? Ein Kursus in 10 Abteilungen“, die sich im Berliner Großstadtleben Ende der 1920er Jahre situiert. Der österreichische Schauspieler Oskar Karlweis (1894-1956) spielte in der Rolle des Kibis einen arbeitslosen jungen Mann, der während der Wirtschaftskrise in Berlin

7 Die wissenshistorische Analyse des Theatertexts der Kabarettrevue und deren Rezensionen lehnt sich an die methodischen Überlegungen von Neumann, Nünning und Hallet zu kulturellem Wissen und Intertextualität sowie an die Untersuchungen von Hulfeld zur theaterhistorischen Wissensgeschichte an, vgl. Neumann und Nünning 2006, Neumann 2006, Hallet 2006, Neumann 2013, Hulfeld 2007.

8 Vgl. Gottfried Keller 2018.

9 Die Novelle über den Aufstieg des unfreiwilligen Hochstaplers Wenzel Strapinski, der als armer Schneider durch allerlei Verwechslungen für einen polnischen Grafen gehalten wird und am Ende sein Glück in Nettchen findet, erschien 1874 und wurde bis 1930 in zahlreichen literarischen, bildlichen, musikalischen und filmischen Adaptionen rezipiert, u.a. 1921 vom Regisseur Hans Steinhoff mit Hermann Thiming in der Hauptrolle (Volo-Film, Wien) und im NS-Regime 1940 von Helmut Käutner mit Heinz Rühmann als Wenzel (Terra-Film, Berlin). Vgl. Gottfried Keller 2018. Forschung zu „Kleider machen Leute“ vgl. Honold 2018. Zur Rezeption Kellers vgl. Amrein 2018. Zur Gottfried Keller-Forschung vgl. Gottfried Keller 1996. 
lebt und eine Beziehung mit seiner Jugendliebe Lis führt, die von der Schauspielerin und Liedermacherin Blandine Ebinger (1899-1993) gespielt wurde. ${ }^{10}$ Nach den literarischen Motiven des Hochstaplers und der Märchenfigur des „Hans im Glück“11 beschließt Kibis, mit Hilfe des Ratgebers reich zu werden, denn: „Na, B. kann warten. Wenn man erst reich ist [...] "12 Beherzt und skrupellos befolgt er die drei Leitsätze zum Reichtum: 1. Du sollst zu allen immer liebenswürdig sein, 2. du sollst dich kleiden wie die Reichen und 3. nur mit ihnen verkehren, dann wirst du auch reich. In der zweiten „Szene“13 mit der Überschrift „Kleider machen Leute“14 gelingt es Kibis dank eines intriganten Verwechslungsspiels, den maßgeschneiderten Anzug für einen „Herrn Direktor“ in einem Herrenmodeladen zu stehlen. ${ }^{15}$ Wie es ihn der 3. Leitsatz lehrt, beendet Kibis kurz darauf die Beziehung

10 Figuren im Werk: „Das Mädchen, das für die Reihenfolge verantwortlich ist“, Kibis, Lis, Der Portier, Geheimrat Regen, Der Schneider, Der Gehilfe, Marie, Madeleine, F.D. Lohrenz, Der Autoverkäufer, Der Oberpostsekretär, Der Geschäftsführer im Modesalon, Der Standesbeamte, Ein Beamter, Küchengäste, Hochzeitsgäste, Mannequins, vgl. Joachimson 1930, o.S.

11 „Hans im Glück“ wurde 1819 als Märchen der Gebrüder Grimm an Stelle 83 (KHM 83) publiziert. Hans' Handlungsweise und Gefühlslage wurde von der Forschung kontrovers interpretiert und musikalisch, literarisch, bildlich und filmisch breit rezipiert (u. a.von Bertolt Brecht „Hans im Glück“, Schauspiel, Fragment von 1919; oder als Spielfilm „Hans im Glück“ [1936], Regie und Drehbuch: Robert Herlth und Walter Röhrig, Produzent: Hermann Schmidt, Erwin Linder [Hans], Georgia Holl [Mädchen], Delta-Film-Produktions- und Verleih [Berlin], Spieldauer: 24 Min.). Zur Forschung vgl. u.a. Uther 2013. Der Theaterkritiker Richard Riedel verweist in seiner Rezension implizit auf das Märchen, wenn er die „Moral“ der Kabarettrevue mit der Gerechtigkeitsformel „Jedem das Seine, jedem das, was ihm zusteht“ zusammenfasst und dafür die „sentimentale“ Figur der Lis (zur „sentimentalen Prosa“ s.w.u.) zitiert: „[...] Dann geht es, wie das Sprichwort rühmt: Gebt jedem das, was ihm geziemt. Hans nimmt sein Gretchen, Jeder sein Mädchen [...]“, vgl. Richard Riedel. 1930. „Wie werde ich reich und glücklich?“. In: Der Tag, 17.06.1930, o.S., Archiv Darstellende Kunst, AdK, Mischa-Spoliansky-Archiv, 626. Zur zeitgenössischen „Hans-imGlück“-Rezeption vgl. Handwörterbuch des deutschen Märchens (1930-1940), vgl. Mackensen 1930.

12 Joachimson, 1930, 8.

13 Joachimson gliedert die Kabarettrevue in zwei Teile. Der erste Teil umfasst sieben „Szenen“, der zweite Teil drei.

14 Vgl. Joachimson 1930, $16-25$.

15 Ein Vergleich mit Kellers Romanfigur, dem Schneidergesellen Wenzel Strapinski, lässt gewisse Ähnlichkeiten in der narrativen Struktur erkennen. Die Stimme des auktorialen Erzählers bei Keller wird bei Joachimson fragmentarisch in der Rolle der Conférencière als pantomimische Szenenansagerin darstellt. Aufgrund Kellers Erzählstimme wird die Konstruktion der Narration deutlich erkennbar. Die Umstände des Zufalls und die selbstbestimmte Identitätssuche Wenzels werden den Leser`innen jedoch in einer spielerisch, leicht erscheinenden Abfolge von Ereignissen dargestellt, sodass der Eindruck entsteht, menschliche Autonomie und Zufälle könnten sich tatsächlich wechselseitig bedingen. Vgl. Selbmann 1985, 32. 
zur mittellosen Lis, da er fortan nur noch mit „reichen Leuten“ verkehren will. ${ }^{16}$ Geschickt arrangiert er über den Geheimrat Regen, einen reichen Automobilkonzerninhaber, dessen Bekanntschaft er im Herrenmodesalon gemacht hatte, ein Treffen mit dessen Tochter Marie, dargestellt von der Theater-, Film-, und späteren Fernsehschauspielerin Annie Mewes (1895-1980).

Nach einem kurzen Verwechslungsspiel entlarvt Marie Kibis’ wahre Identität und stellt ihn, anders als bei Keller, sogleich zur Rede. ${ }^{17}$ Doch Kibis hat „Glück“: Marie lebt seit einiger Zeit ebenfalls nach den Leitsätzen des ihr zugeschickten Glücksratgebers, doch möchte sie statt reich, endlich „glücklich“ werden. Dem zweiten Leitsatz zum „Glück“ folgend, schlägt ihr Kibis vor, sich seiner anzunehmen: „Einen Ärmeren als mich werden Sie wohl kaum finden“. ${ }^{18}$ Marie, erstaunt über die Anwendungslogik des zweiten und dritten Leitsatzes, willigt ein. ${ }^{19}$ Kibis scheint das „Glück“ gepachtet zu haben: Ähnlich wie in Kellers Novelle sticht er in einer temporeichen Handlungsabfolge seinen Nebenbuhler, den Automobilkonzernerben F. D. Lohrenz, aus und wird durch Heirat reich. Das Paar ist zu Beginn des zweiten Teils zwar „reich“ - aber nicht „glücklich“. Weil der Ratgeber offensichtlich bei Marie versagt habe - Kibis wollte ja nur „reich“ werden beschließen sie gemeinsam die Scheidung. Kibis, der plötzlich „glücklich“ werden will, kehrt zu Lis zurück und Marie kommt mit Lohrenz zusammen. In der Schlussszene sind die Paare verheiratet und besingen ihr Liebesglück.

16 Der erste Leitsatz gilt für A. und B. und fordert zur Liebenswürdigkeit auf: „Sei zu jedem liebenswürdig, Keinen stoss zurück, Dann verhilft Dir gern jeder Zu Reichtum und Glück“, vgl. Joachimson 1930, 8. Der 2. und 3. Leitsatz zum Reichtum lauten: „Reichen Leuten musst Du imponieren: Kleide dich wie sie, dann scheinst Du reich, und du kannst mit jedem konkurrieren. Die Fassade macht die Menschen gleich“ und „Als letzten Rat lass Dir bedeuten, Wirf alles ab, was Dich beschwert, Verkehre nur mit reichen Leuten, Denn alles andre ist verkehrt“, vgl. Joachimson 1930, 13, 20.

17 Vgl. Joachimson 1930, 48-54. Bei Keller vergehen drei Monate, ehe der Schwindel auffliegt. Interessanterweise geschieht die Enthüllung seiner wahren Identität während der Aufführung eines parodistischen Schautanzes unter dem Motto „Kleider machen Leute“ durch Wenzels ehemaligen Seldwyler Schneidermeister, vgl. Gottfried Keller 2018, 35-38.

18 Joachimson 1930, 54.

19 2. Leitsatz: „Hilf den Armen und Schwachen, Sie zahlen es zehnfach zurück, Denn Andere glücklich zu machen, Ist der Anfang vom eigenen Glück“ Joachimson 1930, 41. 3. Leitsatz: „Wenn Dir ein Mensch gefällt, such ihn zu halten, Triff die Entscheidung auf den ersten Blick. Man muss den Mut zum ungewohnten haben, Denn ungewöhnlich ist der Weg zum Glück.“ Joachimson 1930, 54. 


\subsection{Eine Gesellschaftssatire über polarisierendes Glückswissen}

Joachimsons Kabarettrevue ist eine moderne Umdeutung der 1874 erschienenen Novelle „Kleider machen Leute“ von Gottfried Keller. Der Bühnenautor aktualisierte die literarische Vorlage für das zeitgenössische Berliner Großstadtpublikum. ${ }^{20}$ Welche Gemeinsamkeiten und Unterschiede lassen sich in der Erzählstruktur, den Figurenkonstellationen und Handlungsmotivationen sowie in der Darstellung von Geschlechterstereotypen in Joachimsons Kabarettrevue erkennen (s. auch Kap. 9.8)?

Ein wesentlicher Unterschied zu Keller ist das Auftreten einer souveränen, weiblichen Hauptfigur namens Marie. Mit der Figur der Marie wird Kibis ein gleichwertiger, parallelverlaufender Handlungsstrang gegenübergestellt. ${ }^{21}$ Die als verwöhnt und dekadent beschriebene 25-jährige Frau ist vom mondänen Großstadtleben und dem Reichtum ihrer Familie gelangweilt. Sie fühlt sich „einsam“, gesellschaftlich unnütz und wünscht sich sehnlichst „glücklich“ zu sein. ${ }^{22}$ Fasziniert vom Glücksversprechen des Ratgeberautors, richtet sie ihr Leben nach seinen Anleitungen aus und befolgt akribisch dessen Leitsätze. ${ }^{23}$ Besessen von der autosuggestiven Optimierungspsychologie bestellt Marie immer mehr Ratgeber. Ihr Vater, Geheimrat Regen, gespielt vom Schauspieler und Kabarettisten Otto Wallburg (1889-1944), fängt die Ratgeber ab und liest die Buchtitel dem Publi-

20 Zur Szenenfolge: Erster Teil: I. Der arme Junge Mann. II. Kleider machen Leute. III. Das reiche junge Mädchen, IV. Auf Wiedersehen, V. Wo bleibt die Marie? VI. Wir haben uns heute getroffen. VII. Wie werde ich glücklich? Zweiter Teil: VIII. Erstens kommt es anders. IX. So ist das Leben, X. Ich bin so glücklich. Vgl. Joachimson 1930, o.S. Zur Rezeption Kellers zwischen 1890 und 1940 vgl. Amrein 2018.

21 Die Szene trägt den Titel: „Das Reiche junge Mädchen“. Vgl. Joachimson 1930, 26-37.

22 „Kein Mensch ahnt, wie einsam ich bin. Ich möchte so gern nützlich sein [...]“, vgl. Joachimson 1930, 29. Dies unterscheidet Marie von Nettchen, der Tochter des Goldacher Amtmannes, die bei Keller, dem kleinbürgerlichen Frauenideal des 19. Jahrhunderts entsprechend, ironisch als tüchtig und freundlich beschrieben wird. Marie ist eine Satire auf einen Typus von Neuen Frauen in den 1920er Jahren, die zwar angeblich emanzipiert verschiedene Männer trifft, sich jedoch weder intellektuell noch wirtschaftlich emanzipiert verhält. Marie hätte studieren und Ärztin oder Anwältin werden können, wie sie selber zugibt, stattdessen geht sie keinem Beruf nach, sondern widmet sie sich lieber den schönen Dingen des Lebens, die sie aber nicht erfüllen.

23 In Anlehnung an den 2. Leitsatz lädt Marie scheinbar „arme Leute“ in ihr Elternhaus ein, die von ihr Suppe und Geld erhalten, doch Max, ein Hausangestellter, verrät seinen Freunden (Schornsteinfeger, Kellner, Milchmann, Müllkutscher) nur, dass sie 20 Mark erhalten werden, was zu reichlich Missverständnissen führt. 
kum vor: „[...] Wie scheine ich mehr als ich bin? [...]“24 Der Geheimrat ist über die naive Gutgläubigkeit seiner Tochter, mit der sie den angeblichen Autoritäten von Ratgeberautor`innen gehorsam Folge leistet, erstaunt. Auch an einer späteren Stelle im Theatertext lässt die Vaterfigur das Publikum resigniert wissen, dass er die Jugend von heute nicht versteht. ${ }^{25}$ Die Figur des Geheimrats verkörpert eine kritische Stimme gegenüber den ambivalenten Glückspraktiken um 1930. Der Bühnenautor deckt durch die Augen des Geheimrats ein politisch polarisiertes Glückswissen auf. Aus seiner Sicht mangele es der jungen Generation an moralischen Grundsätzen, nach denen sie ihr Handeln ausrichten könnten. Stattdessen folgten sie den Versprechungen und Anleitungen von Glücksratgebern, die vorgäben, nur das Beste für die Leser^innen zu wollen. Wallburg singt:

„[...] Ich weiss genau, das alles kann ich lernen,
Ich bin ein Mensch, der seinen Text behält,
Ich weiss, das schreiben lauter kluge Leute,
Ich weiss genau, das kostet nicht viel Geld,
Ich weiss genau, ich kann nur profitieren,
Ich weiss genau, da liegt ne Möglichkeit -
Und trotzdem will ich keine Mark riskieren,
Ich habe Angst vor der Vollkommenheit. [...]“26

Wie ist dieser Passus über die Glücksratgeberpraktik rezeptionshistorisch zu kontextualisieren? Der Theaterkritiker Ernst Jäger nahm den Automobilkonzerninhaber Geheimrat Regen, ein „harmlose[r] und glückliche[r] Reiche[r]“, als ein Stereotyp des „neudeutschen Reichmannstyp[s]“ wahr. ${ }^{27}$ Die Weltwirtschaftskrise

24 Eine Auswahl aus den Bereichen Schönheitspflege, Gesundheit, Sport, Persönlichkeitsentwicklung, Paarbeziehung, Politik und Wirtschaft.: „Wie bleibe ich interessant?“, „Wie küss ich der Dame die Hand“ etc. Vgl. Joachimson 1930, 42.

25, ,[...] Und da bringt man nun, So ein Kind zur Welt, Und man denkt Wunder, was das ist. Und man wickelt es [...] Und man ist glücklich, wenn es frisst. Und man wiegt es ein, Oder man wiegt es ab, Und man zittert vor Angst jedesmal. Und dann sind sie gross, Und dann gehn sie los - Und dann war doch alles egal. Denn - [Refrain] Erstens kommt es anders, Zweitens als man denkt, Was $\mathrm{Du}$ unternimmst, es wird dir nicht geschenkt. Darum leg dich schlafen. Und mach mit allem Schluss. Es kommt alles wie es muss. Es kommt alles wie es muss.“ Joachimson 1930, 73. Dieses Lied, an anderer Stelle von Marie und Kibis gesungen, sowie weitere Chansons aus der Kabarettrevue wurden vielgespielte Gassenhauer, wobei die Verfilmung wesentlich zu deren Popularität beitrug.

26 Zur Beschreibung Wallburgs vgl. Richard Riedel. 1930. „Wie werde ich reich und glücklich?“. In: Der Tag, 17.06.1930, o.S., Archiv Darstellende Kunst, AdK, Mischa-Spoliansky-Archiv, 626. Joachimson 1930, 42.

27 Ernst Jäger. 1930. „Komödie. Wie werde ich reich und glücklich?“. In: Film-Kurier Berlin, 16.05. 1930, o.S., Archiv Darstellende Kunst, AdK, Mischa-Spoliansky-Archiv, 626. 
hatte ihm nichts anhaben können. Im Gegensatz zu seinen Mitstreiter^innen ängstigt er sich vor allzu vielen Veränderungen. Diese seien aber typisch für die Zeit, in der er lebe („Erstens kommt es anders, zweitens als man denkt“) und daher auch nicht aufzuhalten („Es kommt alles wie es muss“). ${ }^{28}$ Umso mehr misstraut er den willkürlich erscheinenden Glückspraktiken der Ratgeberautor^innen, welche die „Möglichkeiten“ zur vermeintlichen „Vollkommenheit“ dank einer neuen „Lebensführung“29 anpriesen. Ausgehend von der Figur des Geheimrats Regen zeigt sich, wie Joachimsons Kabarettrevue als ein gesellschaftspolitischer und -kritischer Kommentar zum zeitgenössischen Krisendiskurs in der Weimarer Republik im Kontext der aufsteigenden nationalsozialistischen Bewegung und deren „rassenideologischen“ Glücksversprechen aufgefasst werden kann. So gewinnen Regens Aussagen im Verlauf des Liedes an politischer Brisanz, wenn er die Ratgebertitel singend vorliest:
„[...] Wie erfahr ich, was morgen geschieht?
Wie stürz ich am schnellsten das Reichskabinett?
Wie werde ich Antisemit? [...]
Wie schliesst man Abrüstungsverträge?
Und wie rüstet man trotzdem recht flott? [...] ]“30

Spätestens in dieser Szene wird deutlich, dass es sich bei der Kabarettrevue des jüdischen Autors Joachimson um eine für die Weimarer Republik gattungstypische $^{31}$ „Zeitsatire“32 handelt: „,...] eine Satire auf Zustände, auf Dogmen, auf Ar-

28 Joachimson 1930, 73.

29 Mehr zur „Lebensführung“ vgl. Schwenk 1996. Mehr zu Weber vgl. Müller 2014.

30 Joachimson 1930, 42.

31 Zur Kabarett-, Theater- und Operettenkultur in Berlin 1890--1945 vgl. Jelavich 1993, Ehrlich und John 1998b, Becker und Niedbalski 2010, Jarchow 2013, Platt, Becker und Linton 2014, Dümling 2015, Morat u. a. 2016, „Jeder einmal in Berlin“ - zur Bedeutung Berlins als Kulturhauptstadt, 28-56. In: Weigel 2017. Zur Vergnügungskultur in Berlin und anderen Großstädten, 1880 -1930, vgl. Rühle 2007, Fischer-Lichte und Warstat 2009, Nolte 2016. Zur Satire in der Weimarer Republik und in NS-Deutschland vgl. Merziger 2010.

32 Zur Musiksatire: Sie ist als eigenständige Kunstform eine Abwandlung des Spott- und Strafgedichts. Es geht darin nicht nur um die Zurschaustellung von menschlichen und gesellschaftlichen Schwächen, Lastern und Mängeln, sondern die M. verhandelt auch kunstästhetische Fragen und weist auf gesellschaftliche Widersprüche hin. Ihre Mittel entlehnt sie der „scherzhaften Parodie: mit der übertreibenden Nachahmung von Texten, Begebenheiten, Verhältnissen, berufstypischen ,Charakteren' und Umgangsformen, sie ist eine Art literarische Karikatur mit Wirkungsabsicht.“ Im Unterschied zur Musikkritik behält sie einen spielerischen Charakter und muss vom Publikum auch nicht vollends akzeptiert werden. Vgl. Braun und Schulz 1997. Braun und Schulz verweisen im Artikel u. a. auf den Musikwissenschaftler Arnold Schering (1877-1941) und seine Definition der M. in drei Arten der Musikkritik (1929). Zur „Zeitsatire“ vgl. N.N. 1930. 
gumente, auf Charaktere [...]“, wie ein Theaterkritiker schrieb. ${ }^{33}$ Joachimson benennt im Theatertext den politischen Aufstieg der nationalsozialistischen Bewegung als Titelgabe für einen Glücksratgeber, welcher eine Bedrohung für den Rechtsstaat darstellen könnte. Er umschreibt eine antisemitische Stimmungslage in der Bevölkerung und er schildert die fortschreitenden Maßnahmen der deutschen Rüstungspolitik, trotz des im Versailler Vertrag festgehaltenen Verbots. ${ }^{34}$ Zieht man in Betracht, dass die NSDAP von lediglich 800.000 Wählerstimmen bei der Reichstagswahl vom 20. Mai 1928 am 14. September 1930, nur wenige Monate nach der Premiere, auf 6,4 Millionen Stimmen angewachsen war und dadurch mit einem Schlag als zweitstärkte Partei mit 107 Abgeordneten in den Reichstag einziehen sollte, wird deutlich, wie weitsichtig Joachimsons Zeitsatire die gesellschaftlichen Glücksdiskurse $\mathrm{zu}$ beurteilten vermochte. ${ }^{35}$

Welche weiteren sprachlichen und theaterästhetischen Mittel kamen zur Untermauerung des kritisch-satirischen Blicks des Bühnenautors auf das ambivalente Glückswissen der Weimarer Republik zum Einsatz?

\subsection{Auftritt der Conférencière: Ein satirischer Kommentar zur Politik der ,Glückskulturen' in der Weimarer Republik}

Die multimedial inszenierte Gesellschaftssatire war bestückt mit fragmentarisch aufblitzenden sprachlichen und visuellen Anspielungen, wie dies auch die Auftritte der Conférencière, gespielt von der Theater-, Film- und Kabarettdarstellerin Dolly Haas (1910-1994), zeigen (Abb. 4). ${ }^{36}$ Haas begleitete pantomimisch die Szenenübergänge, indem sie anstelle einer auktorialen Erzählerstimme mit Hilfe verschiedener Kostüm- und Bildtafelwechseln ironisch-groteske Kommentare für das Publikum mimte. ${ }^{37}$ Ihr parodistischer Auftritt stand in der Tradition des damals, mit einigen prominenten Ausnahmen wie Erika Mann, weitgehend männlichen Kabarett-Conférenciers.

\footnotetext{
„Mischa Spoliansky und Felix Joachimson. Wie werde ich reich und glücklich. Komödie“. In: Die Weltstadt der Berliner. Fremden-Zeitung, o.D., o.S., Archiv Darstellende Kunst, AdK, Archiv-Mischa Spoliansky, 262.

33 N.N. 1930. „Mischa Spoliansky und Felix Joachimson. Wie werde ich reich und glücklich. Komödie“. In: Die Weltstadt der Berliner. Fremden-Zeitung. o.D. o.S. Archiv Darstellende Kunst, AdK, Archiv-Mischa Spoliansky, 262.

34 Zur „Wehrmacht“ in der Weimarer Republik vgl. u.a. Wirsching 2008.

35 Zum sog. „Erdrutschsieg“ von 1930 vgl. Wildt 2008, 54 f.

36 Zu Dolly Haas vgl. Weniger 2011b.

37 Zur Darstellung von Komik, Ironie, Witz, Satire, Parodie, Groteske u.a. in der Komödie vgl. Ellrich 2017.
} 


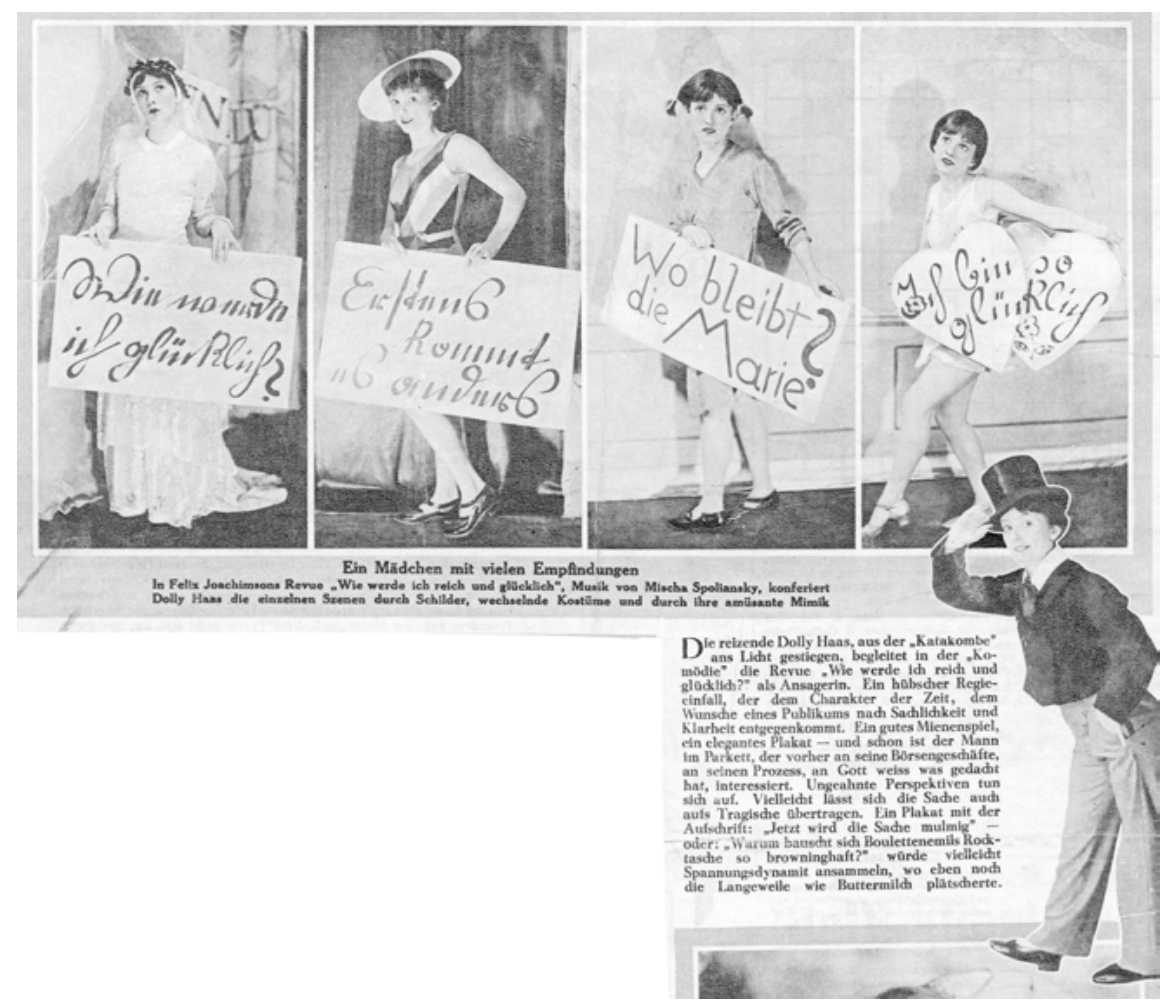

Abb. 4: „Ein Mädchen mit vielen Empfindungen. In Felix Joachimsons Revue ,Wie werde ich reich und glücklich', Musik von Mischa Spoliansky, konferiert Dolly Haas die einzelnen Szenen durch Schilder, wechselnde Kostüme und durch ihre amüsante Mimik.“ [Anonyme Rezension], Berlin, 1930

Ihr kabarettistisches Zwischenspiel, ein typisches Revue-Element, stellte in der Regie von Erich Engel eine Unterbrechung der Szenenabläufe dar. Damit provozierte Haas einen „Verfremdungseffekt“"38 bei Anklängen an ein allzu gefälliges, rauschhaftes Illusionstheater der Gattung Revue, Operette oder Oper. ${ }^{39}$

38 Zum „Verfremdungseffekt“ oder „V-Effekt“ vgl. u.a. Brecht 1973a, Brecht 1973b.

39 Zur Revue s.w.v. Zur Gattung Operette vgl. Quissek 2012. Zur Operette in Berlin 1945-1978 vgl. Schaller 2007, Jarchow 2013, Kauffmann 2017. Bezogen auf die Gattung Oper und dessen verklärende, genussvolle Wirkung durch die Musik auf den Zuschauer schrieb Brecht beispielsweise: „Die Oper, die wir haben, ist die kulinarische Oper. Sie war ein Genußmittel, lange bevor sie eine Ware war. [...] Dieses Unvernünftige an der Oper liegt darin, daß hier rationale Elemente benutzt werden, Plastik und Realität angestrebt, aber zugleich alles durch Musik wieder aufgehoben wird. 
Das Publikum sollte zur kritischen Selbstreflektion über die Inszenierung und deren vorgetragene Inhalte als „etwas Direktes, Lehrhaftes“40 angeregt werden. Dies geschah beispielsweise sprachlich in Form parodierter Metaphern oder in der szenischen Darstellung satirischer Geschlechterstereotypen, wodurch gängige Moralvorstellungen vom Publikum kritisch reflektiert werden sollten. Auf „etwas Unvernünftiges, Unwirkliches und Unernstes“ sollte in einer Inszenierung laut Bertolt Brechts (1898-1956) Theorie zum „Epischen Theater“ auf keinen Fall verzichtet werden, sondern es sollte ,an die rechte Stelle gesetzt, sich selbst aufheben in doppelter Bedeutung. “41 Brechts 1930 erstmals veröffentlichte Überlegungen bezogen sich auf die Oper „Aufstieg und Fall der Stadt Mahagony“ des Komponisten Kurt Weill (1900 -1950), deren Libretto er verfasst hatte. ${ }^{42}$ Eine solche Inszenierung sei „schlechtweg genießerisch“ und „provokatorisch“ zugleich, weil sie „Spaß“ „nicht nur als Form, sondern auch als Gegenstand“ habe. ${ }^{43}$ Auf diese Weise würde, laut Brecht, „Vergnügen“ zum „Gegenstand der Untersuchung “ und nicht umgekehrt. ${ }^{44}$

Der satirische Kommentar, verkörpert in der Rolle der Conférencière, könnte folglich bezweckt haben, dass das mehrheitlich bürgerliche Kurfürstendammpublikum nicht Gefahr lief, einem sozialromantisierenden „Kitsch“ ${ }^{“ 45}$ zu verfallen. Der vergnügliche „Spass“, den die parodistischen Kommentare der Conférencière dem Publikum bereiteten, könnte im Sinne Brechts ambivalenter Doppeldeutigkeit als theaterästhetisches Inszenierungsmittel und zugleich als Vehikel zur satirischen Gesellschaftsanalyse interpretiert werden (wie in den Kapiteln 9.5-9.8 weiterführend aufgezeigt wird).

Ein sterbender Mann ist real. Wenn er zugleich singt, ist die Sphäre der Unvernunft erreicht. [...] der Grad des Genusses hängt direkt vom Grad der Irrealität ab.“ Vgl. Brecht 1957, $16 \mathrm{f}$.

40 Vgl. Brecht 1957, 17. Zum ,Lehrstück‘ bei Friedrich Schiller s. Kap. 15.1-15.3.

41 Brecht 1957, 17.

42 Die Oper entstand 1928/1929 und wurde am 9. März 1930 in Leipzig unter der Regie von Walter Brügmann aufgeführt. Zum Entstehungskontext vgl. „Anmerkungen zu Stücken und Aufführungen“ Hecht 1973. 4^Anmerkungen zu S. 1004.

43 Vgl. Brecht 1957, 18.

44 Vgl. Ebd.

45 Dies galt insbesondere für die Auftritte des mittellosen Liebespaars Kibis und Lis. Zum Zusammenspiel von Kitsch, Glücksempfinden und Musik in der „Ästhetischen Theorie“ bei Theodor Adorno (1903-1969), einem Zeitgenossen Brechts, vgl. u. a. Kutschke 2014. Zu Adornos Ästhetik, Theater, Oper und Brecht vgl. Nowak 2012. Mehr zum zeitgenössischen Diskurs über Revuen und Operetten vgl. Linhardt und Internationale Nestroy-Gesellschaft 2009. 


\section{5 „Erkennt ihr euch?“ Zur Rezension der Kabarettrevue}

Wie wurde diese Aufführung auf Seiten der Rezension von den Theaterkritiker^innen wahrgenommen? Auf einige Kritiker wirkte die Aufführung trotz der eben erwähnten szenischen Einfälle „kitschig-satirisch[ ]“46, „volksstückartig““47, publikumsgefällig, „sentimental“48, und was die Darstellung des „Proletariats“ betraf, vollkommen unzeitgemäß, wenn nicht sogar herablassend. ${ }^{49}$ Auf schmeichlerisch-gefällige Weise parodiere Joachimsons Kabarettrevue das gutbürgerliche Publikum. Ein Theaterkritiker drückte es folgendermaßen aus: „Erkennt ihr euch? [...] und auch sein Publikum erkennt sich gern in den Alltagsgestalten, die da in geschmackvoll wechselndem szenischen Rahmen (Kainer) und apart modisch gekleidet ein kleines alltägliches Spiel aufführen sozusagen lebende Bilder nach bekannten Spruchweisen. ${ }^{\text {50 }}$ Die Moral des Stücks, die beispielweise laute: „Reichtum macht nicht glücklich und Glück lässt sich nicht erkaufen“, sei trivial. ${ }^{51}$ Dolly Haas' ironisierende Auftritte hingegen, wenn sie in einem „freche[n], selbstwusste[n] Tanz“ das vorangegangene Chanson der Lis über das weibliche Stereotyp einer demütig verständnisvollen Frau parodierte, dazu ein elegantes Kleid trug und die Tafel „Kleider machen Leute“ schwenkte, amüsierte nicht nur das Publikum, sondern überzeugte auch die Theaterkritiker. ${ }^{52}$

46 Vgl. Kurt Pinthus [Mai/Juni 1930], „Wie werde ich reich und glücklich?“. In: 8 Uhr, o.S, Archiv Darstellende Kunst, AdK, Mischa-Spoliansky-Archiv, 626.

47 E. Kr. 1930. „Hitze-Theater“. In: Am Montag. Die illustrierte Montagszeitung, 16.06.1930, o.S., Archiv Darstellende Kunst, AdK, Mischa-Spoliansky-Archiv, 626.

48 Vgl. M-o. 1930. „Komödie. ,Wie werde ich reich und glücklich?““. In: Berliner Lokal-Anzeiger, 16.06.1930, o.S., Archiv Darstellende Kunst, AdK, Mischa-Spoliansky-Archiv, 626.

49 Ein Beispiel „,...] Joachims Erfolg ist, dass er sich aufs Volkstümliche stützt. „,,Wir sind armer Leute Kind, du sowohl wie ich', singt das Liebespaar, das sich trennen muß [...]. Sein Schicksal und die Erfahrungen der netten Leute, die sich um das Liebespaar gruppieren, lehren auf einer Kurfürstendammbühne eine Moral, die vom modernen Theater längst überwunden ist: Reichtum macht nicht glücklich, und Glück läßt sich nicht erkaufen. [...]“ Vgl. M-o. 1930. „Komödie. ,Wie werde ich reich und glücklich?““. In: Berliner Lokal-Anzeiger, 16.06.1930, o.S., Archiv Darstellende Kunst, AdK, Mischa-Spoliansky-Archiv, 626.

50 M-o. 1930. „Komödie. „Wie werde ich reich und glücklich?“. In: Berliner Lokal-Anzeiger, Abend-Ausgabe, 16.06.1930, o.S., Archiv Darstellende Kunst, AdK, Mischa-Spoliansky-Archiv, 626. 51 Vgl. ebd.

52 Regieanweisung, vgl. Joachimson 1930, 16. Eine Kritikerstimme: „[...] Man könnte wirklich sentimental werden. Doch das Mädchen, das die einzelnen Bilder ansagt, verrät durch neckische Gebärden, schelmische Bemerkungen und lose Gewandung, wie es in Wirklichkeit gemeint ist. Dolly Haas ist wie geschaffen für diese kleine, aber wichtige Rolle, wie denn überhaupt in der Charakterisierung zeitgemäßer Erscheinungen und im Ausdruck zeitloser Empfindungen nur Vortreffliches geleistet wird.“ Vgl. M-o. 1930. „Komödie. ,Wie werde ich reich und glücklich?““. In: 
Generell bemängelten die Rezensenten die künstlerische Qualität der angeblich zu rein kommerziellen Unterhaltungszwecken aufgeführten Theaterproduktion. So wurde die Aufführung verächtlich als Beispiel für „das Theater als Treibhaus!“53 bezeichnet. Diese Kritik lehnte sich vermutlich an den kulturkritischen Vorwurf des „Zirkus-Reinhardt“54 an. Was war damit gemeint? In seiner gleichnamigen Streitschrift beschrieb der ungarisch-jüdische Theaterkritiker Franz Ferdinand Baumgarten (1880-1927) das Kulturphänomen „Zirkus-Reinhardt“, indem er biologistisch argumentierte:

„Das Zirkus-Theater ist das augenfälligste Beispiel der Kunst- und Kulturzertrümmerung, die wir erleiden. Die symptomatische Bedeutung verleiht dem Reinhardt-Unternehmen und seiner Reklame ein Gewicht, das sie für sich allein nicht hätten. In diesem Spiegel erkennen wir die typischen Merkmale aller Niedergangszeiten, die Krankheitsymptome unserer Zeit “55

Die im Diskurs der ästhetischen Kritik bereits etablierte Polemik gegen das „Zirkus-Theater“, wie das Beispiel des Theaterkritikers Baumgarten zeigt, wurde im Verlauf der 1920er Jahre von den Nationalsozialisten aufgegriffen und als eine kulturrassistische Kampfansage an einen „undeutschen Geist“ auf der Grundlage ihrer „Blut-und-Boden“-Ideologie umgedeutet. ${ }^{56}$ In der antisemitischen NS-Kulturpropaganda gegen jüdische Theaterschaffende und für ein „,arisches“ „Nationaltheater ${ }^{\text {"57 }}$ wurde das avantgardistische Kunst- und Kulturleben ${ }^{58}$ der Weimarer Republik als „entartet“ bezeichnet. ${ }^{59}$

Berliner Lokal-Anzeiger, 16.06.1930, o.S., Archiv Darstellende Kunst, AdK, Mischa-SpolianskyArchiv, 626.

53 Kr 1930. „,Wie werde ich reich und glücklich?‘ Revue von Joachimson und Spoliansky in der Komödie“. In: Berliner illustrierte Nachtausgabe, 16.06.1930, o.S., Archiv Darstellende Kunst, AdK, Mischa-Spoliansky-Archiv, 626.

54 Max Reinhardt (1873-1943) war einer der einflussreichsten deutschsprachigen Theaterintendanten, Direktoren, Dramaturgen, Produzenten, Theater- und Filmregisseure zu Beginn des 20. Jahrhunderts. Er prägte die avantgardistische Theaterästhetik u. a. mit der Verwendung einer Drehbühne. Reinhardt gehörten zeitweilig mehrere Theaterhäuser (1924 gründete er die Komödie am Kurfürstendamm) und war Direktor mehrerer Bühnen in Wien und Berlin, u. a. der Berliner Volksbühne (1915-1918) und des Deutschen Theaters. Aufgrund seiner in den 1920er Jahren zunehmend auf kommerziellen Erfolg und Spektakel orientierten Theaterproduktionen wurden die Bühnen des ehemaligen Avantgardisten als „Zirkus Reinhardt“ kritisiert. Zum zeitgenössischen Vorwurf des „Zirkus Reinhardts“vgl. u. a. Baumgarten 1920. Zu Reinhardt vgl. Fiedler 1975, Marx 2006.

55 Baumgarten 1920, 82.

56 Vgl. Glaser 1997, 167.

57 Ein Beispiel für eine Schriftensammlung zur NS-Theatertheorie: vgl. Bausteine zum deutschen Nationaltheater. Hg. von Walter Stang. Oktober 1933, H. 1, München: Frz. Eher Nchf. Mehr zum „Nationaltheater“-Diskurs im NS-Kontext s. Kap. 15.1-15.3. 
Der Theaterkritiker Ernst Jäger stellte in seiner Rezension über die Kabarettrevue, welche unter Reinhardts Direktion aufgeführt wurde, wiederum einen Vergleich zwischen der spektakelorientierten Theaterästhetik bei Reinhardt und der weiter oben bereits erläuterten kritisch-reflexiven Lehrstücktheorie bei Brecht an:
„[...] Joachimson, Spolianski [sic] und auch Erich Engel würden sich und uns mehr bringen, wenn sie auf ihr schönes Vorrecht, exclusiv [sic] und aggressiv zu sein, wenigstens im Ber- liner Westen nicht verzichten würden. Schon so ganz ,Alles in Reinhardt-Ehren-Ära‘ ange- paßt? [...]“60

Insbesondere Erich Engels Regie wurde in diesem Zusammenhang teils scharf kritisiert. Engel, der während der NS-Zeit vor allem als Filmregisseur erfolgreich weiterarbeiten sollte, hätte die Schauspieler „stramm“ geführt und dabei die szenischen Vorgänge schier ,abgewürgt“. ${ }^{61}$

„Das kritisch-satirische Spielchen hätte ganz leicht und locker hingetupft werden müssen, kichernd über sich selbst und über uns. So aber wusste man nie recht, ob die Derbheiten und Provinzialismen tapsige Hilfslosigkeit oder fehlgeratene Parodie darstellten. “62

Allgemein hätte Engel in seiner Inszenierung ein „viel zu schweres Tempo“ gegenüber der musikalischen Leichtigkeit Spolianskys gewählt. ${ }^{63}$

Die Reaktion der Schweizer Presse auf die Kabarettrevue im Schauspielhaus Zürich, welche am 16. Oktober 1933 Premiere feierte, ist im transnationalen Vergleich aufschlussreich. Das vortreffliche Zusammenspiel aus Regieeinfällen, der

58 Zum Begriff der Avantgarde: „[...] Bezogen auf die künstlerischen Strömungen des 20. Jhs. subsumiert sie die ,Vorreiter aller Gattungen, die sich in programmatischen Schriften [...] oder in artistischen Projekten für eine neue Kunst einsetzen, um mit deren Hilfe eine neue Lebenswirklichkeit zu organisieren. [...] Das zentrale Anliegen der Theater-A. besteht in der radikalen Neustrukturierung eingespielter Wahrnehmungs- und Erfahrungsweisen des Publikums in einer Aufführung“ Vgl. Umathum 2014. Zu den Avantgardediskursen vgl. u. a. Fiebach 1991, Warstat 2011.

59 Mehr zur NS-Kultur- und Theaterpropaganda s. Kap. 15. Vgl. u. a. Weigel 2017.

60 Ernst Jäger. 1930. „Komödie. Wie werde ich reich und glücklich?“. In: Film-Kurier Berlin, 16.05. 1930, o.S., Mischa-Spoliansky-Archiv, 626, AdK.

61 N.N. 1930. „Mischa Spoliansky und Felix Joachimson. Wie werde ich reich und glücklich. Komödie“. In: Die Weltstadt der Berliner. Fremden-Zeitung, o.D., o.S., Archiv-Mischa Spoliansky, 262, AdK.

62 Ebd.

63 Kr 1930. „,Wie werde ich reich und glücklich?` Revue von Joachimson und Spoliansky in der Komödie.“ In: Berliner illustrierte Nachtausgabe, 16.06.1930, o.S., Mischa-Spoliansky-Archiv, 626, AdK. 
schauspielerischen Leistung des internationalen Ensembles und der musikalischen Begleitung wurde von der Theaterkritik für deren „Leichtigkeit“ und „Schwung“ gelobt. Regie führte Eugen Schulz-Breiden (1902-1952), der nach Ende seiner Bühnenverpflichtung am Schauspielhaus (1930-1933) nicht mehr nach Deutschland zurückkehren konnte, sondern nach Österreich gelangte und nach dessen Annexion 1938 nach Kuba und 1940 in die USA auswanderte, wo er als Eugene S. Bryden (auch Eugen Briden) am Broadway wirkte. Der österreichisch-jüdische Komponist und Dirigent Victor Ullmann (1898-1944) war in der Zürcher Produktion für die musikalische Einstudierung verantwortlich. Ullmann kam 1944 im KZ Auschwitz-Birkenbau ums Leben. Die Rolle der Conférencière übernahm die Tänzerin und Kabarettistin Trudi Schoop (1903-1999), Carl Goldner (1900 - 1955) bot eine „Glanzleistung“ als Kibis, Gusti Huber (1914-1933) und Josy Holsten (1897-1963) erfreuten den Kritiker der „Zürichsee Zeitung“ in ihren Rollen als Lis und Marie. Fritz Eßler (1895-1973) gab einen „köstlichen Typen“ als Geheimrat und Siegfried Schürenberg (1900-1993) als Lohrenz. ${ }^{64}$

Die virtuosen, „schmissige[n] und spritzige[n]“65 Kompositionen Spolianskys, zusammen mit seinen arrangierten musikalischen Parodien auf bekannte Melodien, wurden wiederum auch in Berlin im höchsten Maße gelobt. ${ }^{66}$ Spolianskys musikalische Einfälle (Jazz-, Walzer-, Militärmusikmelodien) ${ }^{67}$ stellten transnationale Bezüge zum sozialen, politischen und kulturellen Berliner Großstadtleben während der Weltwirtschaftskrise her und verliehen der Inszenierung, parallel zu den szenischen Vorgängen, den Sprech- und Gesangsparts, der Kostüm- und Lichtgestaltung sowie der Ausstattung des Bühnenraums, eine weitere ästhetische Reflexionsebene.

64 N.N. 1930. „Wie werde ich reich und glücklich?“. In: Zürichsee Zeitung, 16.10.1930, o.S., Nachlass Hans Bänninger, SAPA. Besetzungszettel, vgl. Spielzeit 1930/31,, „Programm“ Schauspielhaus Zürich, SAPA Bern.

65 E. Kr 1930. „Hitze-Theater“. In: Am Montag. Die illustrierte Montagszeitung, 16.06.1930, o.S., Mischa-Spoliansky-Archiv, 626, AdK.

66 „Mischa Spolianskys Musik ist das beste [sic], was man an moderner Programmmusik bisher gehört hat. Sie ist eine ununterbrochene Kette überraschend melodiöser und witziger Einfälle fest gebunden an einen durch Temperament und Stimmung motivierten, köstlich wechselnden Rhythmus und ebenso raffiniert wie sicher abgewogen instrumentiert.“ Vgl. M-o. 1930. „Komödie. ,Wie werde ich reich und glücklich?““. In: Berliner Lokal-Anzeiger, 16.06.1930, o.S., MischaSpoliansky-Archiv, 626, AdK.

67 Vgl. P. M. 1930. „Wie werde ich reich und glücklich. In der Komödie“. In: [UHU?], o.D., o.S., Mischa-Spoliansky-Archiv, 626, AdK. 


\subsection{Der Glücksratgeber: Vehikel zur gesellschaftskritischen Entlarvung ambivalenten Glückswissens}

Vor diesem Hintergrund stellt sich nun die Frage, welche Bedeutung und Funktion dem Objekt des Glückratsgebers in der Kabarettrevue beigemessen wurde. Kein deus ex machina als initialisierendes Auslösungsmoment, wie noch bei Keller in der schicksalhaften Erscheinung des herannahenden Wagens aus Basel, ${ }^{68}$ verhilft den Figuren bei Joachimson zu „Glück“, sondern ein Ratgeberhandbuch mit praktisch anwendbaren Leitsätzen. Diese avantgardistische, antithetische Umdeutung gilt auch für das symbolisch aufgeladene Objekt: Wurden dem Fingerhut bei Keller noch magische Kräfte zugesprochen, ${ }^{69}$ so ist es im Umkehrschluss bei Joachimson das säkulare, populäre Ratgebermedium, mit dessen Anleitungen die Figuren, unabhängig von ihrem sozialen Hintergrund, ihr „Glück“ praktisch, und nicht durch metaphysische Zauberhand, erlangen können.

Als satirische Objektmetapher verstanden, liegt dem Ratgeber zusätzlich zu den dramaturgischen und symbolischen Funktionen ein gesellschaftskritischer Wissenskontext zugrunde: Der Bühnenautor spielte im Handlungsverlauf die diskursive Vielstimmigkeit der konkurrierenden Weltansichten über „Glück“ und „Reichtum“, sprich finanziellen Erfolg, gegeneinander aus - eine dramaturgische Leistung, die keine der eingesehenen Theaterkritiken erwähnte. ${ }^{70}$

Als Vehikel zur satirischen Entlarvung ambivalenter Vorstellungen über Glückswissen diente Joachimson der Glücksratgeber als ein gesellschaftsübergreifendes Kommunikationsmedium. Ähnlich den politischen Flugblättern jener Zeit wird auch der Ratgeber in der Kabarettrevue zu ,bloßen' Reklamezwecken in

68 Vgl. Honold 2018, 74. „Als er bekümmert und geschwächt eine Anhöhe hinaufging, stieß er auf einen neuen bequemen Reisewagen, welchen ein herrschaftlicher Kutscher aus Basel abgeholt hatte und seinen Herren überbrachte, einen fremden Grafen, der irgendwo in der Ostschweiz auf einem [...] Schloss saß. [...].“ Der Kutscher bot Wenzel an, mitzukommen und sich während der Fahrt in den leeren Wagen zu setzen. Als dieser in Goldach einfuhr, wurde er aufgrund seiner vornehmen Kleidung (,seinem schwarzen Sonntagskleide, welches sein einziges war, einen weiten dunkelgrauen Radmantel [...], mit schwarzem Samt ausgeschlagen, der seinem Träger ein edles und romantisches Aussehen verlieh“ [...] Gottfried Keller 2018, 3), für den Grafen gehalten und in den Gasthof „Zur Waage“ zum Essen eingeladen, wo er auf Nettchen treffen sollte. Vgl. Gottfried Keller 2018, $4 \mathrm{f}$.

69 „Der Schneider trug in seiner Tasche nichts als einen Fingerhut, welchen er, in Ermangelung irgendeiner Münze, unablässig zwischen den Fingern drehte, wenn er der Kälte wegen die Hände in die Hosen steckte, und die Finger schmerzten ihn ordentlich von diesem Drehen und Reiben. Denn er hatte wegen des Falliments irgendeines Seldwyler Schneidermeisters seinen Arbeitslohn mit der Arbeit zugleich verlieren und auswandern müssen.“ Vgl. Gottfried Keller 2018, 3.

70 Vgl. Erhaltene Kritiken im Spoliansky-Archiv 626. 
alle Haushalte Berlins verschickt. Die Teilnahme am Programm, einer Lebenspraktik zu „Reichtum“ und „Glück“, beruht auf Freiwilligkeit und ist noch dazu kostenlos. Damit erreicht die Druckschrift alle sich im demokratischen Auflösungsprozess befindenden Bevölkerungsschichten der Weimarer Republik, vom Arbeitslosen bis zur Millionärstochter. So trifft das bürgerlich-konservative und kapitalistische Weltbild von Geheimrat Regen, seiner Tochter und dem Automobilkonzernerben Lohrenz auf die Weltanschauung der sich emanzipierenden und aufstrebenden Arbeiterschicht. Parallel dazu kündigte sich die antisemitische und rechtspopulistische Ideologie der Nationalsozialisten als unheilvolle Sendung in einigen Glücksratgebern an, die sich Marie zuschicken ließ. ${ }^{71}$ Dieser Aspekt der ambivalenten Vielstimmigkeit von Glückswissen wird in diesem Kapitel im Zusammenhang mit Mannheims wissenssoziologischer Schrift nochmals aufgegriffen.

Aus einer wissenshistorischen Perspektive stellt sich die Frage, ob sich die Thesen über die Funktion und Bedeutung des Glücksratgebers als Vehikel zur satirischen Kritik an der als krisenhaft gedeuteten Vielstimmigkeit über „Glück“ jener Zeit anhand Joachimsons Kabarettrevue und deren Rezension beweisen lässt. Die in Pausbacks Ratgeber präsentierten Antworten auf die Frage „Wie werde ich reich und glücklich?" schien das Theaterpublikum auf eine Weise bewegt zu haben, dass es am Ende der Aufführung in einen „langwährenden Beifall“ verfiel. ${ }^{72}$ Warum waren die Zuschauenden, im Gegensatz zu vielen Theaterkritikern, so begeistert vom satirischen Frage-Antwort-Spiel über „Glück“ und „Reichtum“?

Das Thema war brisant. 1930, im „Notopfer- und Arbeitslosenjahr““73, wie ein Theaterkritiker im sozialdemokratischen „Vorwärts“ schrieb, stieg in der Wei-

71 Auf die ,unheilvolle` Verbindung zwischen Glücksratgeberliteratur und NS-Weltanschauung wird weiter unten in diesem Kap. nochmals vertieft eingegangen.

72 Mehrere Theaterrezensionen erwähnten, wie das Publikum Beifall spendete. Aus Berlin: „Diese Musik, Mathematik zu tönender Grazie gewandelt riß die Chansons empor, riß die Darsteller vorwärts, riß das Publikum mit und schließlich zu einem ungewöhnlich lebhaften Beifall hin.“ Vgl. Kurt Pinthus [Mai/Juni 1930], „Wie werde ich reich und glücklich?“. In: 8 Uhr, o.S, Archiv Darstellende Kunst, AdK, Mischa-Spoliansky-Archiv, 626. Ein Beispiel aus München: „Ihm [Heinz Rühmann] und ebenso den übrigen Darstellern dankte schon bei offener Szene und dann zusammengefasst am Schluss vergnügter und langwährender Beifall des amüsierten Haufens.“ Vgl. Hanns Braun. 1930. „Wie werde ich reich und glücklich? Erstaufführung im Schauspielhaus“. In: Münchener Zeitung, 19.01.1931, o.S., Archiv Darstellende Kunst, AdK, Mischa-Spoliansky-Archiv, 626.

73 M.H. 1930. „,Wie werde ich reich und glücklich?‘ Das Notopfer der ,Komödie““. In: Der Abend. Spätausgabe des Vorwärts, 16.06.1930, o.S., Archiv Darstellende Kunst, AdK, Mischa-SpolianskyArchiv, 626. 
marer Republik nach dem Ausbruch der Weltwirtschaftskrise die Zahl der Arbeitslosen auf rund 4 Millionen Anfang 1931 und sollte im Februar 1932 auf über 6 Millionen anwachsen. ${ }^{74}$ Die Kabarettrevue traf mit ihrer kokett anmutenden Frage „Wie werde ich reich und glücklich?“ den Nerv der Zeit. Doch nicht nur Joachimsons fiktive Geschichte über einen Glücksratgeber verhandelte das aktuelle Gesellschaftsgeschehen. Die Lektürepraxis von Ratgebern selbst war eine Modeerscheinung jener Zeit. So kündete es auch die Conférencière im Prolog an, nachdem sie, den Regieanweisungen zufolge, ,als armer Junge verkleidet, ängstlich an die Rampe tritt und sich am Hauptvorhang festhält“"75:

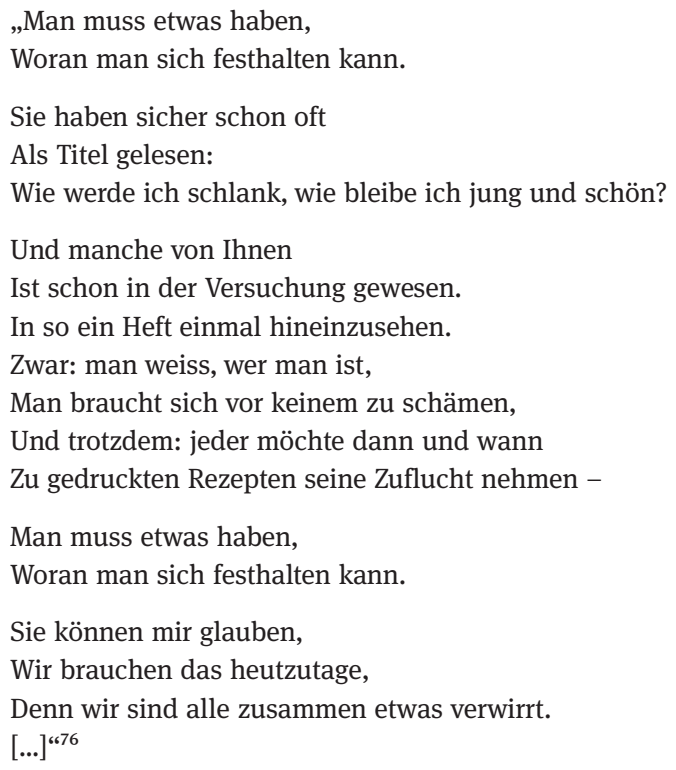

Welches Glückswissen ist dem Prolog zu entnehmen? Will man der Conférencière Glauben schenken, so standen die Figuren des Kibis und der Marie stellvertretend für viele Menschen, welche sich in der modernen Großstadt Berlin orientierungslos fühlten. Eigentlich würde man wissen, wer man sei, so die Conférencière. Und doch, in einem Moment der Orientierungslosigkeit könne man der Versuchung kaum widerstehen, sich einmal von einem Ratgeber anleiten zu lassen. Mit man meinte die Conférencière, mit Blick ins Publikum, anscheinend in erster

74 Vgl. Wildt 2008, 55.

75 Vgl. Joachimson 1930, 2.

76 Ebd. 
Linie die Zuschauerinnen, die sie mit „manche von Ihnen“ ansprach. Das war jedoch eine geschlechterspezifisches Klischee, welches Joachimson im Verlauf des Theatertexts, wie bereits gezeigt, gründlich widerlegte. Vielmehr parodierte der Theaterautor in seiner Kabarettrevue über die Erfolgs- und Glückspraktiken eines Ratgeberhandbuchs geschlechter- und gesellschaftsübergreifende Vorstellungen und diagnostizierte den aktuellen Zustand in der Weimarer Republik als soziale und intellektuelle Krise. ${ }^{77}$ Gleichzeitig bot er den Figuren die Möglichkeit, gesellschaftliche Konventionen zu durchbrechen und mit Hilfe des Glücksratgebers individuelle Handlungsoptionen auszuloten.

Um mehr Erkenntnisse über die gesellschaftlichen Vorstellungen von „Glück“ und die Glücksratgeberpraktiken jener Zeit zu gewinnen und um Wandel, Kontinuitäten und Ambivalenzen genauer bestimmen zu können, wird im folgenden Kapitel danach gefragt, auf welche externen Wissenszusammenhänge Joachimsons Theatertext Bezug genommen haben könnte.

\subsection{Karl Mannheims „Ideologie und Utopie“ (1929). Ein wissenssoziologischer Exkurs}

Eine Antwort auf die Frage, auf welchen wissenshistorischen Kontext der Theatertext von Joachimson betreffend Glückswissen Bezug genommen haben könnte, kann die Denkrichtung der frühen Wissenssoziologie geben, welche sich zu Beginn des 20. Jahrhunderts im Feld der Soziologie, Philosophie und Erkenntnistheorie im deutschsprachigen Raum herausbildete, aber noch keine wissenschaftliche Disziplin darstellte. ${ }^{78}$ Karl Mannheim (1893-1947) gilt vornehmlich als deren Begründer. ${ }^{79}$ Mannheim beschäftigte sich in seiner Schrift „Ideologie und Utopie“ (1929) mit der Frage, wie „Denken [...] wirklich im öffentlichen Leben und in der Politik als ein Instrument kollektiven Handelns funktioniert“. ${ }^{80}$ Dies tat der Soziologe in Abgrenzung zu den etablierten philosophischen Lehrmeinungen zur Logik des Denkens. „Wissenssoziologie“ nannte Mannheim die Methodik, mit der er den „Denktypus“ und dessen „Wandlungen“ analysierte und beschrieb. ${ }^{81}$ „Denkstil[e]“82 bildeten sich seiner Auffassung zufolge innerhalb eines Bedeu-

77 Zum Krisendiskurs in der Weimarer Republik vgl. Eitz 2015, Eitz und Engelhardt 2015.

78 Vgl. Mannheim 2015, 3f.

79 Vgl. Langenohl 2013, 811. Mehr zu Mannheim vgl. u. a. Kettler, Meja und Stehr 1984, Barboza 2009. Zur Rezeption vgl. Meja und Stehr 1982.

80 Vgl. Mannheim 2015, 3.

81 Vgl. ebd., 4.

82 Ebd., 5. 
tungszusammenhangs wechselseitig heraus. Diese gleichzeitig wirkende „Vielfalt der Denkrichtungen“83 konnte sich von „Formen des sogenannten exakten Wissens "84 der empirischen Forschung unterscheiden. Mannheim relativierte damit den Erkenntnisgewinn von „Wissen“85 und entkoppelte ihn von materialistischen und idealistischen Standpunkten. ${ }^{86}$

Sechs Jahre später, 1935, beschrieb auch der Erkenntnistheoretiker Ludwig Fleck (1896 - 1961) eine Vielstimmigkeit von „Denkstil[en]“87 und „Denkkollekti-

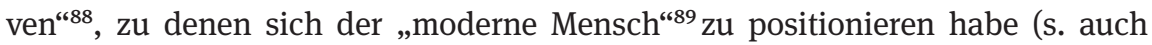
Kap. 11.1). Der polnisch-jüdische Mikrobiologe und Mediziner verfasste im noch nicht von den Nazis besetzten Wien folgenden Gedanken über die „Verwirklichung menschlichen Lebens“:

„Die Verwirklichung menschlichen Lebens äußert sich in der gleichzeitigen Koexistenz vieler verschiedener Denkkollektive und in den gegenseitigen Einflüssen dieser Kollektive aufeinander. Der moderne Mensch gehört - zumindest in Europa - nie ausschließlich und in Ganzheit einem einzigen Kollektiv an. Von Beruf z. B. WissenschaftlerIn, kann er/sie außerdem religiös sein, einer politischen Partei angehören, am Sport teilnehmen usw.“90

Den „gemeinschaftlichen Träger des Denkstiles“ bezeichnet Fleck als „Denkkollektiv.“91 Fleck verwendet den Begriff als „Untersuchungsmittel sozialer Bedingtheit des Denkens“.92 Als „funktionaler“ Begriff bezieht sich der Analysebegriff auf keine „fixe Gruppe“ oder „Gesellschaftsklasse“. ${ }^{93}$ Vielmehr existieren nach Fleck parallel ganz unterschiedliche Denkkollektive, zu denen sich eine Person zugehörig fühlt, und die sich gegenseitig beeinflussen. Dabei unterscheidet Fleck zwischen „zufälligen und momentanen“ Denkkollektiven, die sich

83 Ebd., 7.

84 Ebd., 3.

85 Vgl. Kapitel „Das Entstehen einer dialektisch neuen Situation durch die Expansion des Ideologiebegriffs“. Mannheim 2015, 69-75. Zum „Relationismus“ im Unterschied zum „Relativismus“ von „ortsgebundene[m] Wissen“ vgl. u.a. Mannheim 2015, 71f. Zur Konsequenz für die Geschichtsforschung vgl. Laube 2004.

86 Vgl. Langenohl 2013, 811.

87 Vgl. Fleck 2008, 282.

88 Vgl. ebd., 287.

89 Fleck 1983, 114.

90 Ebd.

91 Vgl. Fleck 2008, 287.

92 Vgl. ebd.

93 Vgl. ebd. 
spontan austauschen und „verhältnismäßig stabile[n]“ sozialen Gruppierungen, die eine „gewisse formelle und inhaltliche Abgeschlossenheit“ besitzen. ${ }^{94}$

Ähnlich wie Fleck ging Mannheim davon aus, dass verschiedene „Gruppen“95 Wissen aus „eine[m] spezifischen Denkstil in einer endlosen Reihe von Reaktionen auf gewisse typische, für ihre gemeinsame Position charakteristische Situation entwickelt haben. “96 Es sei bisher unterschätzt worden, so Mannheim, welche wirkungsmächtigen Konsequenzen dies für die Entscheidungsfindung und das politische und soziale Handeln eines Individuums habe, da dieses strenggenommen nur das weiterdenke, „was andere Menschen vor ihm gedacht haben““.97 Das Handeln von Gruppen sei von der „ererbten Situation mit Denkmodellen“ geleitet, die zur Festigung von sich zwar dynamisch wandelnden, temporär jedoch als allgemeingültig angesehenen, „vorgeformten Denk- und Verhaltensmodellen“ beitragen. ${ }^{98}$ Mannheim sah die ambivalente Pluralität „auseinanderstrebende[r] Denkprozesse“99 in seiner Generation (,unserer Generation“ ${ }^{\text {"100 }}$ ) als problematisch an.

Wie Joachimsons Figuren der Conférencière und des Geheimrats Regen fragte Mannheim nach den Gründen für die Orientierungslosigkeit und die ambivalente Vielstimmigkeit von Wissen. Im Rückgriff auf Max Webers Religionssoziologie ging Mannheim davon aus, dass Gesellschaften dann sozial stabil seien, wenn wenig „vertikale Mobilität“101, das heißt kaum Bewegung zwischen den sozialen „Schichten“ stattfinde. ${ }^{102}$ Dies sei in autoritären Gesellschaften der Fall, in denen nur die Elite in „herrschenden Schichten“ soziales Ansehen und Handlungsmöglichkeit besitze. ${ }^{103}$ Der „Demokratisierungsprozess“104 habe dazu geführt, dass sich eine „intensive, vertikale Mobilität“ zwischen den sich auflösenden Gesellschaftsschichten entwickelt habe. Wissensbestände der „Unterschichten“105, die früher kein öffentliches Gehör gefunden hatten, könnten auf einmal

94 Vgl. ebd.

95 Vgl. Mannheim 2015, 4 ff., ebd., 114.

96 Vgl. Mannheim 2015, 5.

97 Vgl. ebd.

98 Vgl. ebd.

99 Ebd., 8.

100 Ebd., 7.

101 Ebd., 8.

102 Vgl. ebd., 8f. Verweis bei Mannheim, Fußnote 1, 8: „Max Weber, Wirtschaft und Gesellschaft, Bd. 1, Kap. IV. §7, Religionssoziologie: Stände, Klassen und Religion. Tübingen 1925, S. 267-296“.

103 Vgl. Mannheim 2015, 9.

104 Ebd.

105 Ebd. 
den „herrschende[n] Schichten“106 gleichwertig gegenübertreten und deren Denkweisen grundlegend in Frage stellen. Dabei bezieht sich Mannheim auf Georg Lukács (1885-1971), der die Voraussetzung einer Ideologiekritik im kollektiven Erkenntnisprozess eines proletarischen Klassenbewusstseins für möglich hielt. ${ }^{107}$ Die gleichzeitige Inanspruchnahme von Denkstilen, wie beispielsweise politischer Programme, gefährde jedoch die soziale Stabilität der Gesellschaft, so Mannheim. ${ }^{108}$ Mit „Ideologie“"109 beschrieb Mannheim, im Rückgriff ${ }^{110}$ auf die zeitgenössische Ideologieforschung von Georg Adler (1863-1906), Lukács, Weber und Carl Schmitt (1888-1985), die Bildung von Bedeutungszusammenhängen einer Gruppe auf der Grundlage von Machtansprüchen und gemeinsamen sozialen Erfahrungen. Dieser kollektive Erfahrungsschatz löse eine gemeinschaftsstiftende Verbundenheit ${ }^{111}$ aus, wobei eine selbstkritische Reflexion, eine Ideologiekritik, die Widersprüche aufdecken könnte, abhandenkomme. ${ }^{112}$ „Utopien“113 entwerfen bei Mannheim all jene Gruppen, welche die gegenwärtige Gesellschaft als inakzeptabel und daher im Auflösungsprozess begriffen wahrnehmen. ${ }^{114}$

106 Ebd.

107 Vgl. Lukács 1970, Strasen 2013.

108 Vgl. Mannheim 2015, u. a. 60-64.

109 Vgl. u. a. Kapitel: „Der totale Ideologiebegriff stellt die noologische Sphäre des Bewußtseins in Frage“, ebd.

110 Im Kapitel zur „Geschichte des Bedeutungswandels des Ideologiebegriffs“ verweist Mannheim in den Fußnoten 4-10 auf den derzeitigen Forschungsstand und auf die Autoren, die ihn wesentlich beeinflussten, darunter „G[eorg]. Adler, Die Bedeutung der Illusion für Politik und soziales Leben, Jena 1904“, vgl. Adler 1904, und „Carl Schmitt, Politische Romantik, 2. Aufl., München-Leipzig, 1925“.

$111 \mathrm{Zu}$ kollektiven Erinnerungskulturen, kollektivem Gedächtnis, imaginierten Gemeinschaften, Führerkult, vgl. u. a. Anderson 2016, Assmann 1988, Pyta 2010, Assmann 2018. S. auch Kap. 16. 112 Vgl. Mannheim 2015, 3 und Kaube 2015, XV. Mehr zum Begriff des „Politischen“ vgl. Gangl 2008.

113 Vgl. u.a. Kapitel „Im Ideologie- und Utopiegedanken wird die Wirklichkeit gesucht“, Mannheim 2015, 86-94.

114 „Utopie und Ideologie“ muss auch als ein Versuch angesehen werden, Wissenssoziologie auf der Grundlage mangelnder empirischer Beispiele und unausgereifter Begrifflichkeiten als eine neue Erkenntnistheorie zu entwickeln, in der „Politik als Wissenschaft“ (Mannheim 2015, 143) einer Wissenssoziologie befragt wird. Dabei sind Widersprüche und Sackgassen in Mannheims Argumentation nicht selten. Einen Lösungsvorschlag für das skizzierte Dilemma sieht er u.a. in einer zukünftigen, zur Zeit jedoch nicht realisierbaren „Intellektuellenpolitik“ einer Gruppe von „sozial freischwebender Intelligenz“ vgl. ebd., 135. Intellektuelle, welche 1. scheinbar keiner Gesellschaftsschicht zugehörig sind und deshalb 2. Anschluss an die sich bekämpfenden Gesellschaftsklassen finden, 3. die sich durch Bildung aneinander binden (ebd., 136), daher 4. keine Machtansprüche verfolgen, außer als „Wächter“ (ebd., 140) oder Anwälte „der geistigen Inter- 
Es lässt sich die Vermutung anstellen, dass insbesondere die junge Generation der um 1900 geborenen Deutschen, die den Ersten Weltkrieg als Verlierer^innen erlebt hatten, angesichts der „gleichzeitigen Koexistenz vieler verschiedener Denkkollektive und in den gegenseitigen Einflüssen dieser Kollektive aufeinander“ ihre Identität infrage stellte. ${ }^{115}$ Diese jungen Menschen, wie sie stereotypisiert als Marie, Lis, Kibis und F. D. Lohrenz bei Joachimson auf die Theaterbühne traten, suchten nach etwas, an dem sie sich festhalten konnten und seien es nur „gedruckte Rezepte“, welche Reichtum und „Glück“, Schönheit und Erfolg versprachen. Das Fehlen eines eindeutigen, gemeinschaftsstiftenden Bezugspunkts, oder nach Mannheim/Fleck eines einzigen verbindlichen „Denkstils“, wurde von vielen Zeitgenossen als defizitäre Krise interpretiert. ${ }^{116}$

Auch Mannheim diagnostizierte diese Unverbindlichkeit von Denkweisen und deren fehlender Gemeinschaftssinn als gesellschaftliche und intellektuelle Krise. Mit welcher Heftigkeit der Wissenssoziologe die demokratische Pluralität von Denkweisen kritisierte, mag aus heutiger Sicht erstaunen. Sie muss jedoch im historischen Kontext einer sich entwickelnden modernen Konsumgesellschaft in der Weimarer Republik gesehen werden. Das zunehmende Angebot von schulischen, wissenschaftlichen und populären Bildungs- und Medienkonsummöglichkeiten begünstige diese Vielstimmigkeit. Gleichzeitig lösten sich gesellschaftliche Bindungen und moralische Werteinstanzen im Bereich Familie, Religion und Klassenzugehörigkeit langsam auf und wurden durch neue Freiräume zur Entwicklung und Erprobung alternativer Formen individueller Lebensgestaltung ergänzt oder ersetzt. ${ }^{117}$ 1929, im Jahr der Weltwirtschaftskrise, in welchem Wissen eine bisher ungekannte dynamische Vieldeutigkeit erfuhr, lassen sich Mannheims Überlegungen zum relativen Erkenntnisgewinn und seine Ideologiekritik im Spannungsfeld zwischen sich transformierenden Wissensangeboten und einem gesellschaftlichen Bedürfnis nach leicht anwendbaren Ratschlägen auf komplexe Lebensfragen wissenshistorisch kontextualisieren.

essen des Ganzen“ (ebd., 138) und eine gesellschaftliche „Gesamtorientierung“ (ebd., 140) bieten können.

115 Vgl. Fleck 1983, 114.

116 Zum Krisendiskurs in der Weimarer Republik vgl. Eitz 2015, Eitz und Engelhardt 2015.

117 Mehr dazu s. nächstes Kapitel. 


\section{8 „Glück“ als soziale Frage: Ein Vergleich zu Gottfried Kellers „Kleider machen Leute“}

Vor dem Hintergrund von Mannheims wissenssoziologischer Problematisierung gesellschaftlicher Aufstiegsmöglichkeiten und pluraler „Denkstile“ in der Gesellschaft der Weimarer Republik erschließen sich in Joachimsons Theatertext neue Wissenszusammenhänge über „Glück“, „Reichtum“ und „Lebensführung “118. Zieht man nämlich erneut die Theaterrezensionen bei, fällt auf, wie sich einige Kritiker von eher bürgerlichen Zeitschriften amüsiert mit der Figur des Kibis, dem Charakter und der Handlungsweise „dieses sympathischen Mordskerls“119, anfreundeten („Es tut gut, zu sehen, wie gelehrig sich heutzutage die jungen Leute anstellen, um zu Geld und Lebenskomfort zu kommen" ${ }^{\text {“120 }}$ ). Andere Kritiker nahmen aus unterschiedlichen Gründen Abstand von Joachimsons stereotypisierter Figur des sozialen Aufsteigers, wie weiter unten noch gezeigt wird. Welche wissenssoziologischen Zusammenhänge können dabei eine Bedeutung gespielt haben?

Unterschiedliche Denkweisen und gesellschaftliche Vorstellungen von „Glück“ und dem Recht eines Individuums auf persönliches „Glück“ und wirtschaftlichen „Reichtum“ drückten sich in der Parteinahme oder Distanzwahrung gegenüber der Figur des sozialen Aufsteigers aus. Die Theaterkritiker positionierten sich gegenüber Kibis, dem Stereotyp eines sozialen Emporkömmlings, und fragten in ihren Rezensionen nach der Legitimität und der moralischen Handlungsweise eines Erfolg- bzw. Glücksuchenden in der modernen Gesellschaft der Weimarer Republik. Eine gesellschaftliche Meinung gegenüber der stereotypisierten Figur des Kibis spiegelte sich auch in der ambivalenten, um moralische Grundsätze ringenden Figur des Kapitalisten Regen. In seiner Rede als Brautvater drückte er seinen Unmut über die Liaison zwischen dem sozialen Aufsteiger Kibis und seiner Tochter (für die er insgeheim den Automobilerben vorgesehen hatte) in zweideutiger Weise aus:

„[...] Er ist im wahrsten, ehrendsten Sinne dieses

oft missbrauchten Wortes ein selfmade man,

der Vertreter einer Generation, die uns

Älteren im Grund - gestehen wir uns heute

ruhig ein, meine Lieben - nicht sehr

118 Mehr zur „Lebensführung“ vgl. Schwenk 1996. Mehr zu Weber vgl. Müller 2014.

119 P. M. 1930. „Wie werde ich reich und glücklich. In der Komödie“. In: [UHU?], o.D., o.S., Archiv Darstellende Kunst, AdK, Mischa-Spoliansky-Archiv, 626.

120 Sy 1930. „,Wie werde ich reich und glücklich‘. Neue Revue in der Komödie“. In: [Morgenpost?], o.S., Archiv Darstellende Kunst, AdK, Mischa-Spoliansky-Archiv, 626. 
sympathisch ist. Er hat, ohne im Besitze von Barmitteln zu sein, das Herz meiner immerhin vermögenden Tochter im Sturm erobert. [...]“121

Darauf erwiderte Kibis in seiner Rede vor den Hochzeitsgästen:

„Kibis: [...] Wenn

dann also schon geheiratet werden muss, dann

soll es wenigstens eine Frau sein, die Geld

hat. Denn wovon soll schliesslich ein Mann

seine hochgeschätzte Familie ernähren - ?“

„Marie: (stösst ihn).

„Kibis: Und wenn Du mich jetzt auch stösst, Maria, es

Hilft alles nichts, es muss die Wahrheit gesagt werden. [...]“122

Wie reagierten politisch links eingestellte Theaterkritiker auf diese stereotypisierte Beschreibung des sozialen Aufstiegs des mittellosen Kibis? Nachdem der sozialistisch eingestellte Theaterkritiker M. H. die Darstellung des lediglich durch eine gute Heiratspartie reich gewordenen „selfmade man“ gesehen hatte, erstaunt es nicht, dass er in der sozialdemokratischen Zeitschrift „Vorwärts“ einen Verriss über das Stück schrieb. Joachimson ziehe die soziale Frage ins Lächerliche und „verulke“ die „arme[n] Leute“, indem er sie als faul und nutznießerisch darstelle. ${ }^{123}$ Das gutbürgerliche Kurfürstendammpublikum könne sich auf Kosten Kibis’, der als „Prolet“ auftrete, über die „absolute Gemeinheit des Stempelbrüderstandes amüsieren“. ${ }^{124}$ Würde das Stück in einem Berliner Arbeiterviertel wie Wedding oder an der Frankfurter Allee in Nähe zu Friedrichshain aufgeführt, hätte das Publikum das Theater „demolier[t]““. ${ }^{125}$ Die Wirkungsmacht im ästhetischen Zusammenspiel aus szenischen Vorgängen und musikalischer Untermalung mutiere zur „Giftnummer“ ${ }^{126}$ Für das Publikum hätte diese Form der gefälligen Unterhaltungskultur weitreichende Folgen:

121 Joachimson 1930, $57 \mathrm{f}$.

122 Ebd., 59.

123 M.H. 1930. „,Wie werde ich reich und glücklich?‘ Das Notopfer der ,Komödie““. In: Der Abend. Spätausgabe des Vorwärts, 16.06.1930, o.S., Archiv Darstellende Kunst, AdK, MischaSpoliansky-Archiv, 626.

124 Ebd.

125 Ebd.

126 Ebd. 
„Er [Spoliansky] schläfert die Widerstandkraft des Verstandes ein. Er verdummt den Zuhörer, indem er ihn durch Musik windelweich und kindlich macht. Je besser, je bunter dieser Unsinn musikalisch und szenisch hergerichtet wird, je flotter Oskar Karlweis den proletarischen Hanswurst mimt, je rührender Blandine Ebinger das süße Mädel, je wabbliger Wallburg den fetten Millionär, desto abscheulicher und unwürdiger wirkt das alles.“127

Wie hätte Joachimson auf diesen Brechtschen Vorwurf, eine den Verstand der Zuschauer vernebelnde Theaterästhetik zu entwerfen, reagiert? Der Theaterkritiker unterstellte dem Autor, dieser hätte sich in einem solchen Fall herauszureden versucht, indem er darauf hingewiesen hätte, dass er nur die Reichen parodieren wollte. ${ }^{128}$

Eine weitere mögliche Antwort lässt sich aufzeigen, indem man sich der literarischen Vorlage, der transnational rezipierten Novelle „Kleider machen Leute“ des Schweizers Gottfried Keller, zuwendet und diese hinsichtlich der sozialen Frage in den Wissenszusammenhängen der Erzählstruktur untersucht.

Keller nimmt in seiner Novelle in gewisser Weise eine sozialkritische Perspektive ein. Er befragt mit den Figuren des mittellosen Schneidergesellen Wenzel und des tüchtigen und freundlichen Nettchens ${ }^{129}$ die Möglichkeit einer autonomen Identitätssuche und, mit Mannheim gesprochen, einer ,vertikalen Mobilität“130 im 19. Jahrhundert. ${ }^{131}$ Dabei stellt Keller, ähnlich dem „Spielmodell einer verkehrten Welt“132, das Individuum vor die sozialexperimentelle Wahl zwischen einem entbehrungsreichen Schneiderleben, einem Leben als ungewolltem Hochstapler und einem Leben im privaten „Glück“. Der Entstehungshintergrund der Novelle liefert weitere Hinweise für dieses Argument.

„Kleider machen Leute“ ist Teil des Novellenzyklus „Die Leute von Seldwyla“, welcher erstmals 1856 und in erweiterter Fassung 1873/74 erschienen ist. Keller lebte von 1861 bis 1876 in Zürich und war als Staatsschreiber angestellt, bis er ab 1876 als selbständiger Schriftsteller leben konnte. ${ }^{133}$ Im Vorwort zur zweiten, erweiterten Fassung von 1873/74, welche „Kleider machen Leute“ enthält, gibt der

127 Ebd. Mit „kindlich“ meinte M.H. vermutlich ,naiv“.

128 Ebd.

129 Aus der Perspektive der historischen Geschlechterforschung ist die Verwendung des Substantivs im Neutrum sowie „nett“ als substantiviertes Adjektiv, als Verdinglichung des Frauennamens, stereotypisierend zu verstehen und widerspiegelt die ironisch-satirische Haltung des Autors gegenüber der weiblichen Figur. Zu Wissensgeschichte und Geschlecht vgl. Braun 2006, Braun 2013.

130 Mannheim 2015, 8.

131 Vgl. Selbmann 1985, 39.

132 Vgl. Honold 2018, 73.

133 Vgl. ebd., 53. 
Autor einen Einblick in die Referenzpunkte der Novellen. Die Stadt Seldwyla sei zwar fiktiv, doch trügen die Geschichten über die Bewohner*innen sowohl historische als auch zeitgenössische Züge. Keller beobachtete im Verlauf der Niederschrift seiner Novellen (ab 1850), wie sich das „Wesen“134 der Menschen verändert hätte. Der wirtschaftliche Aufschwung hätte immer mehr „Seldwyler“ in „Geschäftsleute[...]“ verwandelt, die nun mit „eleganten kleinen Notizbüchern“ geldwirtschaftliche Spekulationen betreiben würden:

„Immer sind sie in Bewegung und kommen mit aller Welt in Berührung. Sie spielen mit den angesehensten Geschäftsmännern Karten und verstehen es vortrefflich, zwischen dem Ausspielen schnelle Antworten auf Geschäftsfragen zu geben [...].“135

Hier werden Parallelen zu Joachimsons Kabarettrevue offensichtlich: Keller nahm ein zunehmendes Streben nach kapitalistischer Vermögensanreicherung wahr, das mit einer erhöhten Geschäftigkeit und Mobilität einhergehen würde. Dieser sozialwirtschaftliche Wandel beeinflusse und verändere die Gemütslage der Geschäftsleute, so Keller. Sie seien unglücklich, würden weniger lachen und seien „einsilbiger und trockener geworden“. ${ }^{136}$ Mit Blick auf den Entstehungskontext sollten Kellers Novellen folglich nicht ausschließlich in der Tradition der volkstümlichen Erzählung einer „sentimentalen Prosa“137 verstanden werden. Vielmehr sollten sie, nach Honold, als ein „Produkt einer gesellschaftlich wie individuell krisenhaften Umbruchszeit“, als ein „eher unfreiwillig ,modernes“ Literatur-Dokument [...] ,realistischen“ Erzählens“"138 begriffen werden. Im transnationalen Vergleich sind bei beiden Autoren (Keller/Joachimson) folglich „soziale Mobilität“139, Gefühlswandel und Selbstdarstellung von zentraler Bedeutung. ${ }^{140}$

134 Gottfried Keller 2018, 61.

135 Ebd., $60 \mathrm{f}$.

136 Vgl. ebd., 60.

137 Zeitgenössischer Lexikoneintrag zur „Sentimentale[n] Prosa“: „[...] die Gefühlsprosa, deren Zweck die ästhetische Darstellung der Gefühle ist nach deren innerlich unmittelbarem Seyn und Leben. [...]“ Wilhelm Hebenstreit. 1843. Wissenschaftlich-literarische Encyklopädie der Aesthetik. Ein etymologisch-kritisches Wörterbuch der ästhetischen Kunstsprache, Wien: Carl Gerold Verlag, 709. Zur Definition „Sentimentaler Prosa (Gefühls-Prosa)“ bei Hillebrand: „§ 293. [...] Die wahre ästhetische Gefühlsprosa ist die freie Sprache des Herzens, insofern sie in schöner, unmetrischer Form die wirklichen Bewegungen desselben darlegt. [...]“ Joseph Hillebrand. 1827. Lehrbuch der Literar-Aesthetik oder Theorie und Geschichte der schönen Literatur mit besonderer Berücksichtigung der deutschen zum Selbststudium und Gebrauche bei Vorträgen. Bd. 2. Mainz: Florian Kupferberg, 355-361, 355.

138 Vgl. Honold 2018, 53.

139 Zur Begriffsdefinition bspw. beim russisch-amerikanischen Soziologen Pititrim Sorokin, vgl. Ders. 1927. Social Mobility. New York: Harper. 
Unabhängig von ihrem sozialen Hintergrund gehen die Geschlechter bei Keller und Joachimson mit der sozialen Macht ihres Erscheinungsbildes, ihrem manierlichen Benehmen und dem Verbergen oder Offenlegen ihrer inneren Befindlichkeiten unterschiedlich um: Kibis (anders als der ,kultiviert' auftretende und zugleich über die Verwechslung peinlich berührte Wenzel ${ }^{141}$ ) bricht in mehrfacher Hinsicht mit den gesellschaftlichen Konventionen. Auf die Gefahr hin, sich unbeliebt zu machen, lässt Kibis jeweils Lis, Marie, und später den Geheimrat ungeniert wissen, welche egoistischen Absichten er hegt, nämlich den finanziellen und sozialen Aufstieg. Die Erzählstrategie will es, dass ihn sein jeweiliges Gegenüber (Lis/Marie/Geheimrat) in seinen Handlungsabsichten gewähren lässt. Marie hingegen behält ihre Gefühle, ihr Einsamkeitsempfinden und ihr Unglücklichsein, sowohl vor der Begegnung mit Kibis als auch nach der Eheschließung für sich. Doch nach 3-monatigem Eheunglück lüftet auch sie den Schleier der Selbstdarstellung und stellt Kibis zur Rede. ${ }^{142}$ Ob er denn in der Ehe mit ihr „glücklich“ sei? Dieser erwidert, dass ,Glücklichsein“ ja nie sein Plan gewesen wäre. Da Marie aber unglücklich sei und der Ratgeber offensichtlich bei ihr versagt hätte, beschließen sie gemeinsam die Scheidung. ${ }^{143}$

Was war der Auslöser für Maries Handeln? Abermals war es der Ratgeber. Im „Anhang: Wie erhalte ich mein Eheglück?“"144 stellt sie fest, dass nicht Kibis dem darin entworfenen Bild des perfekten Ehemannes entspricht, sondern F. D. Lohrenz. Dieser verkörpert im Stück den Typus des karrierebewussten, zielstrebigen und dynamischen Geschäftsmannes, „de[n] personifizierte[n] Eilbetrieb unserer

140 Vgl. Honold 2018, 74. Honold fasst die Lektion bei Keller folgendermaßen zusammen: „Wenn Kleider Leute machen, statt umgekehrt, dann kann auch und gerade ein armer Schneider aus seinem dienenden, abhängigen Dasein ausbrechen und sich zum Meister seiner Existenz aufschwingen. Das Strukturgesetz dieser Geschichte ist demzufolge die Umkehrung.“ Vgl. Honold 2018, 73.

141 Zur Begegnung zwischen Wenzel (getarnt als Graf) und Nettchen bei Keller: „Der Wanderer nahm schnell seine Mütze vom Kopfe und machte ehrfurchtsvolle, ja furchtsame Verbeugungen, von Rot übergossen. Denn eine neue Wendung war eingetreten, ein Fräulein beschritt den Schauplatz der Ereignisse. [...] die Schüchternheit, Demut und Ehrerbietung eines so vornehmen und interessanten jungen Edelmanns erschien ihr durch den Sinn, ja hinreißend. Da sieht man, fuhr es ihr durch den Sinn, je nobler, desto bescheidener und unverdorbener [...].“ Vgl. Gottfried Keller 2018, $18 \mathrm{f}$.

142 Zur genderhistorischen Forschung hinsichtlich Selbstdarstellungsmitteln und Rollenstereotypen an deutschsprachigen Theatern vom 18. Jh. bis in die NS-Zeit vgl. u.a. HochholdingerReiterer 2014.

143 Hier unterscheidet sich Marie wesentlich von Nettchen, die bei Wenzel bleibt. Vgl. Joachimson 1930, 67-71.

144 Vgl. Joachimson 1930, $63 \mathrm{f}$. 
Tage“, wie ein Theaterkritiker schrieb. ${ }^{145}$ Sein berufliches Leben ist hektisch und voller Termine. Er findet keine ruhige Minute, in der er endlich einmal Marie um ihre Hand hätte bitten können. Das Glückswissen über die Moral dieser Liaison könnte lauten: Für beide Protagonist^innen war das Liebesglück zum Greifen nahe gewesen, doch mussten sie es erst verlieren (Lohrenz) bzw. erkennen (Marie), um es (wieder)zufinden. Dasselbe gilt für Kibis, der nach der Scheidung blitzartig zu Lis zurückkehrt, um „glücklich“ zu werden. ${ }^{146}$ „[...] Denn Geld und Glück, das sind doch nicht dieselben Begriffe. Was zwar nicht neu, aber zu beweisen war“, wie ein Theaterkritiker über die Moral der Kabarettrevue urteilt. ${ }^{147}$

Welche Antwort gibt der Bühnenautor auf die soziale Frage auf der Suche nach „Glück“ und „Erfolg“ seiner Protagonist*innen? Gegen Ende des Stücks besucht Kibis gemeinsam mit Lohrenz, Marie und Regen eine Modeschau und trifft dort auf die elegante Erscheinung der Lis. Sie tritt auf, als hätte sie seit der Trennung eine persönliche Entwicklung durchlebt („Ich bin kein kleines Mädel mehr. Ich bin eine Dame.“148). Doch innert Minuten wird klar, dass Kibis in ihr immer noch das kleine Mädchen sieht („Du bist einfach Lis! Genau wie früher“"149). Ihrer Erwiderung, sie lasse sich aber von ihm nicht mehr so behandeln, entgegnet er chauvinistisch: „Das kommt auch noch.“"150 Sein Fazit lautet schmeichlerisch: „Weißt Du, zum Glücklichsein gehört ein anderer Mensch, den man selbst glücklich machen kann. “151 In der letzten Szene „Ich bin so glücklich“ heiraten die Liebespaare Marie/Lohrenz und Kibis/Lis ihren sozialen Schichten entsprechend und besingen darin ihr gemeinsames „Glück“. Nur der Geheimrat schüttelt über all dieser Irrungen und Wirrungen den Kopf. ${ }^{152} \mathrm{Ob}$ sie alle wirklich „glücklich“ miteinander werden, bleibt offen.

145 Vgl. Ernst Jäger. 1930. „Komödie. Wie werde ich reich und glücklich?“. In: Film-Kurier Berlin, 16.05.1930, o.S., Archiv Darstellende Kunst, AdK, Mischa-Spoliansky-Archiv, 626.

146 Vgl. Joachimson 1930, 80.

147 Kr 1930. „,Wie werde ich reich und glücklich?‘ Revue von Joachimson und Spoliansky in der Komödie.“ In: Berliner illustrierte Nachtausgabe, 16.06.1930, o.S., Archiv Darstellende Kunst, AdK, Mischa-Spoliansky-Archiv, 626.

148 Joachimson 1930, 80.

149 Ebd.

150 Ebd.

151 Ebd.

152 „[...] Ich frage nicht nach dem Warum, Mir ist das schon lange zu dumm. [...]“ Joachimson 1930, 86. 


\subsection{Fazit}

Die Untersuchung hat gezeigt, dass der Glücksratgeber, getreu den stilistischen Mitteln einer Kabarettrevue „in populärer, leichtfasslicher Form“"153, je nach Lebenssituation der Protagonistinnen ambivalente Anleitungen für eine „glücklichere“ oder finanziell erfolgreichere Lebensführung bot. Geschlechter- oder sozialpolitische Fragen hatten für den fiktiven Ratgeberautor Dr. Pausback keine Bedeutung. Pausback setzte in seinem Ratgeber mit seinen imaginierten Glücksversprechen und praktischen Anleitungen, kombiniert mit unterschiedlichen diskursiven Wissenskollektiven, eine integrative, gesellschaftsübergreifende Wirkungsmacht voraus. Dies bezeugt sein Werbeschreiben. So die Theorie. Den anwendungspraktischen Wissensraum der Lehrsätze entwarf Joachimson jedoch nicht in einer zukünftigen, modernen, klassenlosen Gesellschaftsutopie. Als Satiriker beschloss er, die soziale Mobilität nur soweit zu treiben, bis in der Figur der Marie die Erkenntnis erwacht, dass sie in Lohrenz einen viel liebenswürdigeren Ehemann finden würde als im narzisstischen Kibis. Ganz nebenbei ist die Figur des Lohrenz reich - ein sozioökonomischer Umstand, der als satirischer Kommentar bewertet werden dürfte.

Die zu Beginn aufgeworfene Frage des Ratgebers „Wie werde ich reich und glücklich?“ ist nicht zuletzt eine moralische Frage. Der Lösungsvorschlag des Ratgeberautors ist eine mit Hilfe anleitender Lehrsätze neuzugestaltende Lebensführung. Welche weiterführenden Antworten auf die moralische Frage nach „Glück“ und „Reichtum“ hat die Untersuchung aufzeigen können? Joachimsons musikalische Gesellschaftssatire bleibt in ihrer Antwort ambivalent. Mit den stilistischen Mitteln der Ironie, Parodie und Groteske deckt sie menschliche Schwächen der stereotypisierten Figuren auf. Damit parodiert und provoziert sie das Publikum. Gesellschaftliche Vorstellungen von „Glück“ und „Reichtum“ werden von ihr spielerisch infrage gestellt, ohne verbindliche Antworten zu geben. Dadurch bleibt sie in ihren Aussagen ambivalent und entzieht sich der Verantwortung, ein ernsthaftes moralisches Urteil zu fällen.

Aus diesem Grund könnte argumentiert werden, dass Joachimsons Gesellschaftssatire nicht den Anspruch erheben muss, im Sinne Brechts ein moralisches Lehrstück ${ }^{154}$ zu sein, oder (wie ein echter Ratgeber) Lehrsätze einer vermeintlich idealen Lebensführung zum Erlangen von „Glück“ und „Reichtum“ zu vermitteln. Die literarische Vorlage bei Keller sowie die Wahl des Ratgebers als heimliche Hauptfigur lassen vermuten, dass Joachimson dem Publikum, wenn nicht eine

153 Vgl. Brief von Dr. Pausback an die Empfänger des Glücksratgebers, Joachimson 1930, 7. 154 Mehr zur Theateraufführung als ,Lehrstück' s. Kap. 15 u. 16. 
dogmatische, dann aber vielleicht mehrere vielstimmige Versionen von Glückswissen vermitteln wollte. Am Ende konnte sich das Publikum seine eigene Meinung darüber bilden. ${ }^{155} \mathrm{Im}$ Rückgriff auf die eingangs formulierte These konnte aufgezeigt werden, dass der Bühnenautor mit dem Vehikel des Glücksratgebers und dessen ambivalenten Glückspraktiken die Vielstimmigkeit von Glückswissen als Krisendiagnose um 1930 zum zentralen Thema seiner Gesellschaftssatire erhob.

In der Schlussszene wird eine weitere, für die vorliegende Untersuchung erkenntnisreiche wissenssoziologische Aussage über „Glück“ gemacht: Der Autor schließt den Glücks- und Erfolgskursus mit der reaktionär anmutenden Entscheidung, dass die Paare nur ihren sozialen Schichten entsprechend ihr "Glück“ finden können. Die gesellschaftliche Ordnung der Weimarer Republik, wie Joachimson sie satirisch entwirft, bleibt trotz Demokratisierungsprozessen (die eine soziale Mobilität ermöglichten) und vielstimmiger „Denkstile“156 (denen sich laut Fleck moderne Menschen zugehörig fühlen können) erstaunlich starr und erneuerungsresistent. Die Schlussszene dürfte als eine parodistische Übertreibung einer Zeitsatire im Sinne der Gattung Kabarettrevue (einer Komödientradition aus dem 19. Jahrhundert) verstanden werden. Mit ihr übte der Bühnenautor an den gesellschaftlichen Zuständen in der Weimarer Republik, namentlich den konkurrierenden Glücksdiskursen und den trotz Demokratisierungsbestrebungen nur langsam aufbrechenden sozialen Entfaltungsmöglichkeiten, spöttisch Kritik.

Um die ambivalente Politik der ,Glückskulturen' wissenshistorisch weiter zu erforschen, wird sich die Untersuchung im folgenden Kapitel den praktischen Anleitungen in der vielseitigen Glücksratgeberliteratur zuwenden. Die Analysebeispiele veranschaulichen, wie gesellschaftspolitisches Glückswissen mit Psychowissen (also psychologischem und psychoanalytischem Wissen aus der Ratgeberliteratur und Arbeitspsychologie) im Übergang von der Weimarer Republik zum Nationalsozialismus auf radikale Weise verschränkt wurde.

155 In Kap. 15 und 16 wird der Aspekt ,Lehrstück' nochmals aufgegriffen. 156 Vgl. Mannheim 2015, 5. 